\title{
Elementos para la crítica \\ de la economía política de la pobreza
}

\author{
Julio Boltvinik
}

El artículo crítica el enfoque convencional o economía política de la pobreza (EPP), fundamento del nuevo enfoque (paradigma en ciernes) de la pobreza y el florecimiento humano que el autor ha desarrollado recientemente (se incluye un resumen del mismo). Los objetos de la crítica son: el utilitarismo, los enfoques de la opulencia o el ingreso real, la teoría neoclásica del consumidor, los enfoques de capabilities de Sen y Nussbaum, las definiciones de pobreza, y el objeto de la EPP (conceptos de necesidades, satisfactores y recursos). En los dos últimos casos es una crítica externa, que parte del nuevo enfoque desarrollado, muestra el reduccionismo múltiple de la EPP y por qué resulta inevitable en el paradigma vigente.

PALABRAS CLAVE: pobreza, florecimiento humano, crítica, necesidades, satisfactores.

This paper presents a critique of the traditional approach or political economy of poverty (PEP), which is the basis of the new focus (or paradigm in the making) of poverty and human flourishing recently developed by the author (of which a summary is included). The critique analyses utilitarianism, the opulence approach or real income approach, the neoclassical theory of consumer behaviour, Sen and Nusbaum's capabilities approaches, the definitions of poverty and the object of study of PEP (the concepts of needs, satisfiers and resources). In the last two cases the critique is external and stems from the newly developed approach that shows the multiple reductionism in which PEP incurs and why it is unavoidable within the prevailing paradigm.

KEY WORDS: poverty, human flourishing, critique, needs, satisfiers. JULIO BOLTVINIK: El Colegio de México, México-Distrito Federal
jbolt@colmex.mx

Desacatos, núm. 23, enero-abril 2007, pp. 53-86.

Recepción: 8 de octubre de 2006 / Aceptación: 8 de noviembre de 2006 


\section{CRÍTICA INTERNAY CRÍTICA EXTERNA. CONTENIDO DEL ENSAYO}

$\mathrm{R}$ ecientemente he terminado una extensa obra que esboza un nuevo enfoque de la pobreza y que la vincula estrechamente al concepto de florecimiento humano. Este trabajo será referido de aquí en adelante como Ampliar la mirada (Boltvinik, 2006). El presente artículo tiene por objeto presentar los aspectos más generales de la crítica del estudio convencional (vigente, dominante o vulgar) de la pobreza, dominado por la economía neoclásica, sobre la cual se ha apoyado la formulación del nuevo enfoque. Espero convencer al lector de que el título de este artículo es correcto: que el objeto de la crítica puede ser llamado economía política de la pobreza (EPP). Para que el lector pueda apreciar el resultado al cual esta crítica ha conducido, en la sección 2 sintetizo los elementos constitutivos del nuevo enfoque.

En los trabajos que desarrollé en los dos decenios finales del siglo pasado, abordé lo que ahora, en retrospectiva, puedo llamar la crítica interna del estudio de la pobreza
El fruto propositivo, elaborado a partir de tal crítica interna, fue el Método de Medición Integrada de la Pobreza (MMIP) ${ }^{1}$. El contenido central de la crítica interna de los métodos de medición de la pobreza usuales (directos e indirectos) es que se basan sólo en una parte de las fuentes de bienestar de los hogares (sobre este concepto véase más adelante el inciso 7.2) y que, por tanto, son incapaces de ordenar correctamente a los hogares en términos de su nivel de vida, lo que los lleva a una identificación parcial y sesgada de los hogares pobres. En el MMIP combino la información sobre las seis fuentes de bienestar en una concepción de la pobreza entendida como las carencias humanas derivadas de las restricciones en dichas fuentes. En la segunda parte de Ampliar la mirada se expone en detalle esta crítica interna y se confronta con el MMIP.

A pesar de la ampliación de la mirada en cuanto a las fuentes de bienestar, la perspectiva desde la cual se hace esta crítica sigue siendo una que se sitúa de manera di-

\footnotetext{
${ }^{1}$ El planteamiento consolidado original (hubo algunos otros prelimi-
} nares escritos en 1990 y 1991), se encuentra en Julio Boltvinik, 1992. recta en el eje del nivel de vida, al igual que los enfoques criticados. Es decir, se trata de una crítica interna que se sitúa en el mismo paradigma metodológico en el cual se ubican los objetos de la crítica. Identifico este paradigma metodológico como: "es válido estudiar la pobreza situándose, desde un principio, en el eje del nivel de vida", lo cual conlleva el rechazo (implícito) de la vía consistente en partir de un eje conceptual más amplio (como el que he llamado florecimiento humano). Este paradigma no está explícito en la formulación de ningún autor y sólo se percibe cuando uno se sale de él y formula uno nuevo. Al formular el nuevo enfoque metodológico (llamémosle paradigma, aunque no lo sea 'aún') se identifica la negación que conlleva y que consiste en sostener que "es un error empezar por el eje de nivel de vida" cuando se estudian el nivel de vida, la pobreza y la desigualdad. A esta afirmación le he llamado tesis crítica y se presenta en el inciso 7.3 de este artículo.

Apoyándome en dicha tesis crítica y en los demás elementos de crítica al estudio convencional de la pobreza que aquí se sintetizan, y que en conjunto constituyen la crítica externa de la economía política de la pobreza, he construido el nuevo paradigma que afirma que para llevar a cabo adecuadamente el estudio de la pobreza y el nivel de vida es necesario definir primero los elementos constitutivos del eje de florecimiento humano, es decir, definir qué es el florecimiento humano (lo cual supone basarse en una reflexión sobre la esencia humana) y, a partir de ello, recortar perspectivas para ubicarse en el eje del nivel de vida, concebido (ahora) como la perspectiva económica del eje de florecimiento humano. Con ello podemos identificar, aunque sea todavía en términos muy generales, como se hace en Ampliar la mirada, cuáles son las potencialidades de los seres humanos y adoptar esas potencialidades como normas de referencia para comparar, contra ellas, la situación observada de las personas. Lo que los estudiosos de la pobreza y del nivel de vida no habían hecho era reflexionar sistemáticamente sobre el ser humano (qué es, qué necesita, qué capacidades y potencialidades tiene). Es esta la tarea que he emprendido en la primera parte de Ampliar la mirada². La

\footnotetext{
${ }^{2}$ Aunque fue sólo en Ampliar la mirada donde emprendí esta tarea de
} 
bibliografía sobre esta materia está casi totalmente escindida de la de pobreza.

Además, la tarea emprendida en Ampliar la mirada me ha permitido formular una respuesta propia (basada en György Márkus) a la pregunta sobre los elementos constitutivos de los ejes conceptuales aplicables al estudio del florecimiento humano, el nivel de vida y la pobreza: el desarrollo de las fuerzas esenciales humanas (necesidades y capacidades).

Es decir, que el nuevo enfoque construido tiene dos pilares: 1) la definición metodológica (o nuevo paradigma metodológico) consistente en derivar el eje del nivel de vida del eje de florecimiento humano; y 2) la definición del contenido conceptual de ambos ejes, consistente en identificar el desarrollo de las fuerzas esenciales humanas como su elemento constitutivo. Para lograr lo primero era necesario fundar, sobre la base de la crítica del camino metodológico directo, el camino indirecto propuesto para llegar al eje del nivel de vida. Es la tesis crítica. Para lograr lo segundo era necesario fundar la respuesta propia por dos vías:

1. Una crítica de las respuestas existentes. A lo largo de Ampliar la mirada se critican de manera indirecta, a través del análisis del pensamiento de Amartya Sen, las respuestas del utilitarismo (incorporando también la crítica a éste de John Rawls) que sostiene que el elemento constitutivo es la utilidad; la respuesta de Rawls que postula como tal "los bienes primarios"; y el de los bienes y servicios o ingreso real (que Sen llama de la opulencia). De manera directa (e indirecta a través de varios autores) se critican, además, el enfoque de los capabilities y functionings de Sen (capítulo 8); la teoría neoclásica del consumidor (capítulo 10); y las concepciones y definiciones de pobreza de diversos autores. Todas estas críticas, a la par de la tesis crítica, constituyen la crítica externa de la EPP.

2. Un análisis constructivo de las mejores respuestas (que giran en torno a las necesidades humanas o conceptos

manera sistemática, era una necesidad sentida desde muchos años atrás y había llevado a cabo una búsqueda fragmentaria, que ha quedado plasmada en Boltvinik, 1990: cap. 1, así como en Boltvinik y Hernández Laos, 1999.

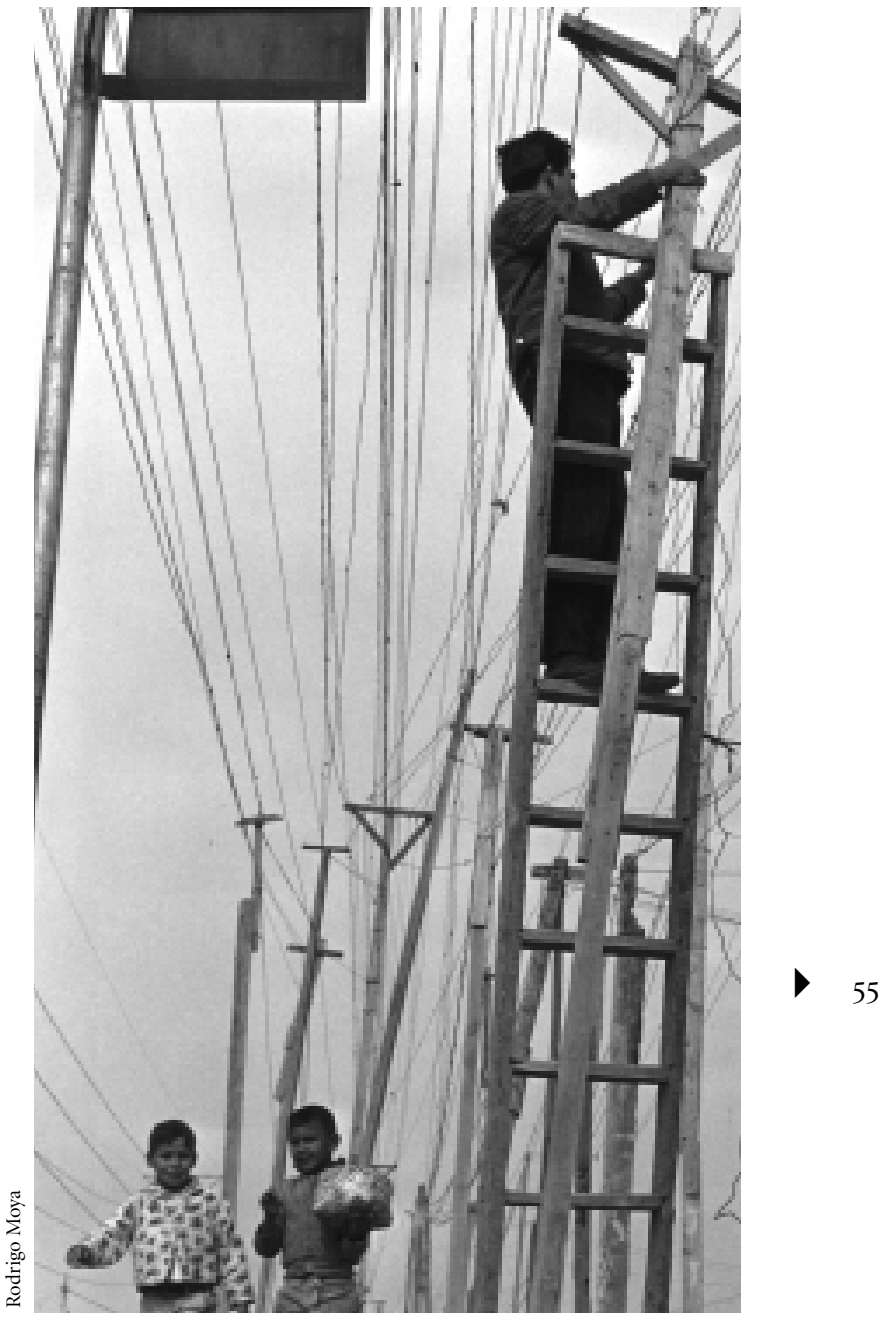

Ciudad Nezahualcóyotl, Estado de México, ca. 1965.

cercanos) a la pregunta sobre la definición de los elementos constitutivos del eje de florecimiento humano (EFH), la cual constituye lo que he llamado la primera pregunta fundacional. La lectura de diversos autores se hizo, esencialmente, como búsqueda de la respuesta a dicha pregunta. La siguiente idea de Marx sirvió de punto de partida y se sometió, de una manera más bien implícita, a prueba con las ideas de los diversos autores que se examinan en la primera parte del libro: la riqueza humana como desarrollo de las capacidades y necesidades humanas (fuerzas esenciales humanas) que 
constituyen una unidad dialéctica, lo que Marx llamó determinaciones reflexivas ${ }^{3}$. La lectura minuciosa de Maslow, Fromm, Maccoby, Max Neef, Doyal y Gough, Nussbaum, Desai, Alkire, confirmó que los mejores análisis de las necesidades humanas terminan vinculándolas, entrelazándolas, con las capacidades humanas (aunque casi siempre de manera implícita, no consciente). La postulación del desarrollo de la unidad necesidades-capacidades, de las fuerzas esenciales humanas, como el elemento constitutivo del EFH es consecuencia de un hallazgo reiterado: esta unidad está en el fondo de los conceptos y argumentos de dichos autores.

La crítica externa presentada en este ensayo comprende cinco aspectos: 1) la crítica de Sen y Rawls al utilitarismo, complementada con la crítica del primero al enfoque de la opulencia y otros enfoques cercanos (sección 3); 2) una síntesis de la crítica externa a la teoría neoclásica del consumidor realizada en el capítulo 10 de Ampliar la mirada (sección 4) que complementa las críticas al utilitarismo; 3) una ultra-síntesis de las críticas al enfoque de pliar la mirada (sección 5); 4) la crítica de las definiciones convencionales de pobreza (sección 6); y 5) la crítica del objeto de la EPP a través de sus "mapas conceptuales", que reconstruyo con sus conceptos de necesidades, satisfactores y recursos (sección 7), que incluye la tesis crítica y muestra el reduccionismo múltiple que la EPP conlleva. A diferencia de la crítica interna que he venido haciendo por casi cinco lustros, la que aquí presento no es una crítica de los métodos de medición y de sus implicaciones de política pública, pero la complementa al concentrarse en la fundamentación conceptual de la EPP. En los dos últimos aspectos la crítica se lleva a cabo contrastando las posturas criticadas con el nuevo enfoque, lo que hace evidente su carácter externo.

\footnotetext{
${ }^{3}$ Véase, al respecto, György Márkus, 1986: 53, así como el capítulo de esta obra traducido en este número de Desacatos y la presentación, a mi cargo, de dicho texto.
}

\section{SÍNTESIS DEL NUEVO ENFOQUE DE LA POBREZAY EL FLORECIMIENTO HUMANO}

La visión recientemente desarrollada del florecimiento humano ${ }^{4}$ de la pobreza se puede sintetizar en los siguientes párrafos:

1. Defino lo bueno como florecimiento humano, al que entiendo como desarrollo de las fuerzas esenciales humanas, es decir, como desarrollo y satisfacción de necesidades, y desarrollo y aplicación de capacidades.

2. El objetivo último de las políticas públicas debería ser (en un Estado ideal, probablemente utópico) el pleno florecimiento humano de todos.

3. Distingo riqueza y pobreza humanas de riqueza y pobreza económicas. Dentro de cada una distingo la dimensión del ser y la del estar (ser o estar rico/pobre). El ser de la riqueza (pobreza) humana caracteriza a quien necesita mucho (poco) y ha (no ha) desarrollado sus capacidades en profundidad y en extensión. El estar de la riqueza/pobreza humana se define por el grado de satisfacción de las necesidades y de aplicación de las capacidades efectivamente desarrolladas por el individuo.

4. El florecimiento humano lo podemos concebir, siguiendo a Marx y a György Márkus, como la realización de la esencia humana en la existencia individual concreta, la medida en la cual el individuo se despliega libre y multilateralmente a través del desarrollo y ampliación de sus necesidades y capacidades, que tienden, como su conciencia y su ser social, a la universalidad.

\footnotetext{
${ }^{4}$ Podría haber elegido términos más conocidos como bienestar o desarrollo humano, pero ambos están cargados de significados ajenos y distantes al planteamiento desarrollado en Ampliar la mirada. Bienestar, además, sólo alude (en el mejor de los casos, cuando no se asocia con el utilitarismo) a las necesidades pero no a las capacidades. Desarrollo humano, que sería un término más amplio (y, por tanto, más cercano a florecimiento) está cargado de ciertos significados particulares derivados del enfoque en la materia del Programa de las Naciones Unidas para el Desarrollo (PNUD), por una parte, y de una corriente de la psicología por la otra. Florecimiento humano, como dice Thomas Pogge, conlleva la evaluación "más comprehensiva, todo-inclusiva, de la calidad de las vidas humanas. Es un concepto más amplio que muchos otros conceptos que señalan evaluaciones más específicas -incluyendo las de placer, bien-estar (wellbeing), bienestar (welfare), opulencia y virtud [...]" (2002: 27).
} 
El ser humano necesita ir más allá de la satisfacción de sus necesidades deficitarias (los tres primeros niveles en la jerarquía de Maslow: necesidades fisiológicas, de seguridad y de afecto/pertenencia). Para el florecimiento humano se requiere también que, a través del trabajo o del amor, o mejor de los dos, la persona realice lo que potencialmente es como ser humano, como ser que comparte la esencia de la especie: su potencial de universalidad, de libertad, de creatividad, de conciencia.

5. Sin embargo, durante el largo periodo de la alienación, de la prevalencia de la división social espontánea del trabajo, pueden coexistir la creciente universalidad del 'ser humano', es decir, la multilateralidad social, con la creciente unilateralidad de los individuos. Por tanto, resulta necesario realizar la evaluación tanto a nivel societal como individual, subdividiendo el eje de florecimiento humano en estos dos niveles, llamándole progreso social al primero y desarrollo de las fuerzas esenciales humanas al segundo. El progreso social lo podemos concebir como la constitución de los presupuestos de un desarrollo irreprimido y rápido de las fuerzas esenciales humanas. Siguiendo lo planteado en el parágrafo 3 , tanto el nivel societal como individual del eje de florecimiento humano se subdivide en dos: la dimensión del ser y la del estar. A nivel societal se distinguen la creación de las condiciones (presupuestos) para el desarrollo de las necesidades y capacidades (en la dimensión del ser) y la creación de las condiciones para la satisfacción de las necesidades y para la aplicación de las capacidades (en la dimensión del estar). A nivel individual se subdivide en el ser y el estar de la pobreza/riqueza humana.

6. Cuando se recorta el eje conceptual de florecimiento humano para quedarse únicamente con la perspectiva económica del mismo, se delimita el eje conceptual de nivel de vida, en el que podemos ubicar la pobreza/ riqueza económica. El eje del nivel de vida es, entonces, la perspectiva económica del florecimiento humano. Si bien en ambos ejes está el ser humano con todas sus necesidades y capacidades, el ser humano completo, en el eje del nivel de vida lo miramos sólo desde la perspectiva económica: desde el punto de vista de los recursos y condiciones económicas (empleo y condiciones de trabajo, por ejemplo). Igual que con pobreza/riqueza humana, en la pobreza/riqueza económica podemos distinguir la dimensión del ser y del estar. La pobreza económica es sólo el primer obstáculo a vencer para que el florecimiento humano sea posible. Pero es un obstáculo que la inmensa mayoría de los habitantes del planeta no han superado. El otro obstáculo importante es la alienación. Si la persona se ve obligada, para sobrevivir, a vender lo único que posee, su propio cuerpo y mente y las capacidades y conocimientos, pocos o muchos, que haya podido desarrollar; si lo único que posee lo usa alguien más por ocho o más horas diarias, ¿qué es la persona? Si en ese uso que otro hace de sus capacidades humanas la persona no se siente realizada, no siente sus fuerzas esenciales transformando al mundo y transformándose a sí misma, si sólo siente cansancio y tedio, si siente el producto del trabajo como algo ajeno, y si además éste le pertenece, efectivamente, al patrón, ¿qué sentido tiene que la paga recibida sea suficiente para sobrevivir si al día siguiente, y al año siguiente, será igual? Esto es lo que Marx llamó la alienación. La pobreza y la alienación son los dos obstáculos fundamentales para el florecimiento humano.

7. Podemos entonces distinguir cuatro conceptos de pobreza/riqueza: 1) humana del ser; 2) humana del estar; 3) económica del ser; 4) económica del estar. Estas categorías son distintas a la categoría usual de pobreza, que si bien se acerca a la económica del estar, tampoco coincide con ella, por dos razones: primero, porque la usual no se deriva de un recorte del eje de florecimiento humano sino que se aborda directamente como parte del eje de nivel de vida; y segundo, porque incluso en las mejores aplicaciones suele incorporar sólo una parte de las necesidades humanas (casi siempre las llamadas materiales), en contraste con la perspectiva económica de todas las necesidades humanas en el nuevo enfoque desarrollado, y deja fuera las capacidades humanas (en el sentido usual del término, que no puede identificarse con las capabilities ni los functionings de $\left.\operatorname{Sen}^{5}\right)$.

${ }^{5}$ En Ampliar la mirada la obra de Sen se analiza en dos extensos capítulos. Ahí se documenta el sentido auténtico de los términos capabi- 


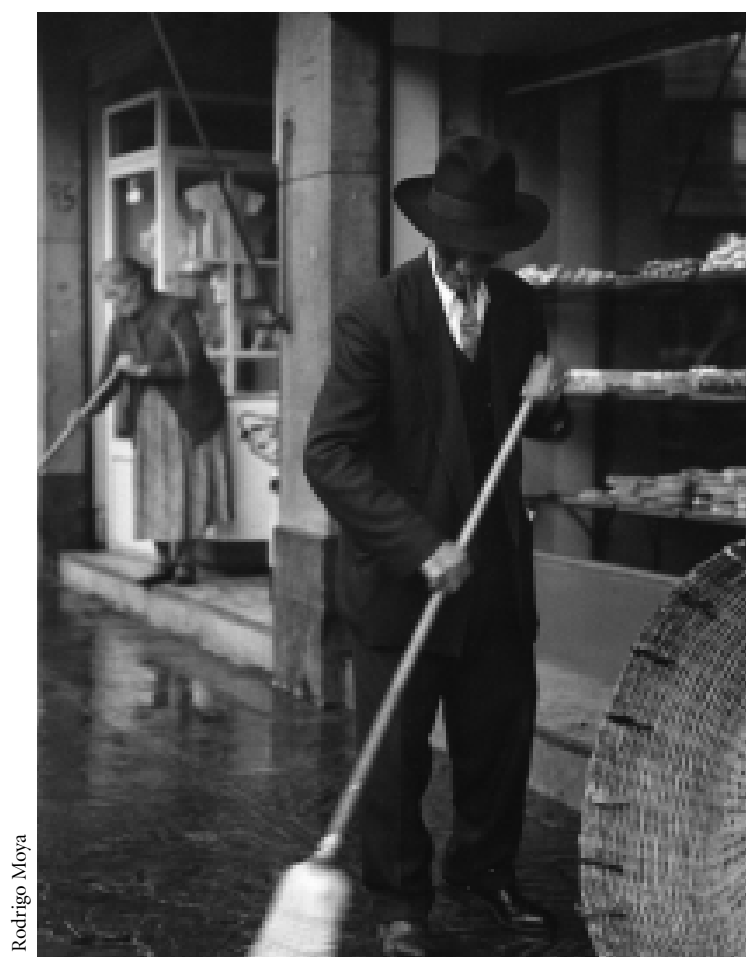

San Rafael, ciudad de México, 1957.

8. Al introducir capacidades para constituir la dupla necesidades-capacidades, y además al hacer explícito que el eje del nivel de vida es sólo un eje derivado del de florecimiento humano, la lógica del estudio de estos temas (pobreza, nivel de vida, florecimiento humano) se transforma radicalmente. Se hace evidente la interacción entre necesidades y capacidades. La persona bien alimentada, sana y educada puede desa-

lities y functionings y se argumenta que no pueden traducirse al español sin confundir al lector. Ninguno de los dos se refiere a las capacidades humanas en el sentido usual del término, que es el que nos permite hablar, por ejemplo, de capacidades psicomotoras, cognitivas, destrezas y habilidades. Capabilities se refiere más bien a oportunidades económicas derivadas de los recursos que se poseen, mientras que functionings se refiere a estados del individuo o la persona. Para apreciar que ninguno se acerca al concepto de capacidades, basta notar que no tiene sentido hablar del desarrollo y la aplicación de las capabilities o de los functionings, y que Sen nunca habla de tal desarrollo y aplicación, a pesar de que son éstos los elementos centrales cuando hablamos de capacidades. rrollar ciertas capacidades de trabajo. Aquí queda claro cómo la satisfacción de necesidades hace posible el desarrollo de capacidades en las personas. Pero en las sociedades capitalistas, las capacidades individuales tienen que venderse en el mercado de trabajo para poderse aplicar. Esta venta puede ser para un trabajo de sobrevivencia (Franz Kafka haciendo un trabajo que odia en una oficina) o para un trabajo de autorrealización (un científico haciendo investigación de punta en un laboratorio público o privado). En el primer caso el individuo sólo aplica algunas de sus capacidades menores, mientras que en el segundo aplica sus capacidades fundamentales y las desarrolla. En el primer caso se logra la supervivencia; en el segundo, el florecimiento humano con las restricciones que este concepto puede tener bajo el capitalismo. Pero las capacidades tienen que venderse no sólo para aplicarse (y seguirse desarrollando) sino para hacer posible la satisfacción de las necesidades, que a su vez hacen posible la reproducción de la capacidad. Esta circularidad, esta integralidad entre capacidades y necesidades, se pierde en los enfoques actuales que sólo miran, en el mejor de los casos, un lado del asunto.

9. Estamos acostumbrados a pensar en las necesidades en términos de satisfacción. Pensamos en ellas en términos estáticos, como si el bebé recién nacido tuviese las mismas necesidades que la persona adulta. Para ilustrar qué se quiere decir con el desarrollo de las necesidades, podemos empezar por hablar de extensión de las mismas. Si, por ejemplo, tomamos el esquema de necesidades de Maslow (necesidades fisiológicas, seguridad, amor y pertenencia, estima y autorrealización, que conforman su jerarquía de necesidades, más dos necesidades no incluidas en ella: las cognitivas y las estéticas) resulta claro que no todas las personas adultas han desarrollado las siete necesidades: los 'pobres' (en el sentido convencional, por eso lo escribo entre comillas simples, mientras más extrema sea su pobreza más tajante es lo que sigue) pueden estar dominados por las necesidades fisiológicas y las demás necesidades pueden casi no existir. Otras personas que no son 'pobres' pueden haber quedado atrapadas en alguna necesidad insatisfecha, como el afecto, y no haber de- 
sarrollado la necesidad de estima ni la de autorrealización; muchos no desarrollan las necesidades estéticas, y en cuanto a las cognitivas, la mayor parte se queda en los niveles elementales de las mismas, que son los niveles asociados a la satisfacción de las necesidades básicas iniciales. Por tanto, sí es posible hablar del desarrollo de las necesidades en el sentido de su extensión. Una persona con las necesidades extensionalmente desarrolladas tendrá las siete necesidades identificadas por Maslow y predominará en ella la motivación al crecimiento, siendo la autorrealización la necesidad primordial. Pero por desarrollo de las necesidades también debemos entender su desarrollo cualitativo, su humanización creciente o, quizás de manera más clara, su profundización. Tómese la necesidad de entendimiento o, como la formula Erich Fromm, la necesidad de un marco de orientación y devoción. Muchas personas se aferran a la educación religiosa recibida y dan por satisfecha esa necesidad. Para otras, en cambio, es una búsqueda interminable. Quien desechó el mito bíblico de Adán y Eva puede buscar apasionadamente entender a fondo el origen del ser humano. Hay entonces una gama muy amplia para el desarrollo de esta necesidad. Por otra parte, prácticamente todas las necesidades humanas están siempre humanizadas, incluyendo las fisiológicas, como lo está la alimentación en el gourmet. Este segundo sentido de desarrollo de las necesidades humanas es el de profundización y humanización.

10. La esperanza de muchos seres humanos, que viven para sobrevivir, está fincada en el tiempo libre. Al margen del trabajo de sobrevivencia, piensan que en el tiempo libre podrán hacer lo que siempre han querido hacer o convertirse en lo que siempre quisieron ser (como Kafka, que escribía en el tiempo libre que le dejaba un trabajo que odiaba). La mayoría, sin embargo, termina desperdiciando ese valioso, escaso o abundante tiempo libre frente al televisor viendo programas chatarra que ni siquiera lo enriquecen culturalmente.

11. Dos consecuencias de este enfoque son: la ruptura radical con las visiones disciplinarias usuales y la superación de los conceptos construidos a partir de ellas.
La visión del ser humano completo requiere una comprensión transdisciplinaria como punto de partida, antes de poder abordar fructíferamente las perspectivas disciplinarias, como la económica del nivel de vida.

\section{LAS CRÍTICAS DE SEN Y RAWLS AL UTILITARISMO ${ }^{6}$}

Amartya Sen define las teorías de la utilidad como las que ven valor sólo en la utilidad individual, definida en términos de alguna métrica psicológica como placer o felicidad. La importancia moral de las necesidades, en esta interpretación, se basa sólo en la noción de utilidad, dice Sen, quien distingue el utilitarismo del bienestarismo. El primero se propone maximizar la utilidad social total, igualando las utilidades marginales de todos. En el segundo se mantiene la utilidad como valor único pero no se busca maximizar la utilidad social total.

Si se acepta el principio primo que la igualdad de las utilidades totales de todas las personas es valiosa, dice Sen, el utilitarismo debe ser condenado. Introduce aquí la diversidad humana, concepto que se repetirá una y otra vez en su obra, y que en este caso explica que la igualación de las utilidades totales de cada persona y la igualación de sus utilidades marginales arrojen resultados diferentes. Sen también critica al utilitarismo usando el "método de las implicaciones del caso": entre un lisiado que obtiene un bajo nivel de utilidad de un nivel dado de ingreso y un mago del placer, el utilitarismo concentraría el ingreso en el segundo, mostrando que no percibe el principio primo mencionado.

La crítica central de Sen al bienestarismo hace notar que la adaptación que el pobre lleva a cabo para reconciliarse con su situación significa que puede sentir un gran placer con muy pequeñas cosas, por lo que en la métrica

\footnotetext{
${ }^{6}$ Lo expresado en esta sección es una apretada síntesis de la sección 7.1 de Ampliar la mirada. Las obras de Sen en las cuales me he basado para el análisis de su crítica al utilitarismo son Sen, 1980, 1987 y 1992. Las críticas de Rawls al utilitarismo las he obtenido indirectamente, de Sen y de Cohen (véase adelante).
} 
de la utilidad los pobres resignados pueden ser muy eficientes productores de utilidad. Esta crítica y la de los gustos caros de Rawls (véase adelante) son simétricas y, para resaltarlo, conviene llamar crítica de gustos baratos a la crítica que lleva a cabo Sen. Combinando ambas críticas podríamos concluir que la medición de la utilidad (si fuese posible) podría ubicar en mejor posición (utilidad total más alta) a los pobres que a los ricos. Por tanto, el igualitarista bienestarista que busca igualar la utilidad total de todas las personas exigiría transferencias de los pobres a los ricos. Pero, paradójicamente, el utilitarista transferiría recursos de los ricos a los pobres, que son "magos del placer", para aumentar la utilidad social total. Sen no rechaza del todo el enfoque bienestarista: lo que rechaza es que el bien-estar pueda ser juzgado exclusivamente en términos de sus utilidades.

G. A. Cohen (1993) identifica las críticas de gustos ofensivos y de gustos caros de Rawls con el utilitarismo. La primera sostiene que el placer derivado de discriminar a otros o someterlos a libertades disminuidas no debe contar en el cálculo de la justicia. La segunda rechaza que se deba proveer al gourmet con un ingreso más alto que a la persona de gustos modestos, ya que los ciudadanos son responsables de sus preferencias. Estas son críticas irrefutables en mi opinión y muestran los severos límites de todo enfoque que, como dice Penz, suponga que los individuos son la única autoridad para juzgar lo correcto de sus apetencias (lo que incluye, como veremos, al enfoque de capabilities de Sen) sin atreverse a formular ningún principio universal ni juicio de valor alguno.

Sen vuelve a introducir la diversidad personal para criticar lo que él llama el "enfoque de la opulencia" (EO), que consiste en identificar como elemento constitutivo del eje del nivel de vida el acceso a bienes y servicios o el ingreso real de las personas: una persona con tasa metabólica más alta, argumenta, puede resultar peor nutrida que otra de ingresos más bajos. Concluye que el nivel de vida no es una cuestión de opulencia sino de la vida que uno lleva, de lo que podemos hacer y de lo que podemos ser/estar. Sen identifica el "Enfoque sobre las necesidades básicas para el desarrollo" (ENBD) con el EO, con el argumento de que las necesidades básicas son típicamente formuladas en términos de posesión de bienes y lo cri- tica por no ahondar en el aspecto fundacional del problema, que identifica con la pregunta sobre por qué son importantes las necesidades básicas.

Las variaciones en los requerimientos nutricionales han sido reconocidas en la bibliografía sobre mediciones de pobreza. Por ello no se entiende cuál es el fantasma contra el que Sen pelea. Una vez que ha derrotado al utilitarismo, ya que su crítica de gustos baratos es demoledora, lo que tendría que refutar para fundar su enfoque de capabilities no es la postura de la opulencia sino la que sostiene que el elemento constitutivo del nivel de vida es la satisfacción (objetiva) de las necesidades humanas. Pero esta última postura no la ve Sen.

Con similares argumentos Sen (véase sobre todo Sen, 1992) critica el enfoque de los bienes primarios de Rawls: según aquél, el índice de bienes primarios que propone Rawls para medir la situación de las personas no toma en cuenta la diversidad humana y, por tanto, no reconoce la desventaja de utilidad del lisiado. Rawls proponía posponer este problema y no ignorarlo, reconoce Sen, pero en su opinión una teoría de la justicia no puede posponer esta cuestión, ya que las diferencias de necesidades son omnipresentes. Sen concibe los bienes primarios como medios de propósito general para la búsqueda de las diferentes ideas de lo bueno.

Para valorar la importancia de la diversidad en la que insiste Sen, en Ampliar la mirada exploro qué tan serias serían las desigualdades persistentes si todos los hogares tuviesen los mismos recursos por persona. Concluyo que serían desigualdades de tercera importancia.

\section{CRÍTICA EXTERNA DE LATEORÍA NEOCLÁSICA DEL CONSUMIDOR}

Para el economista ortodoxo, la 'objetividad' de la necesidad es sospechosa. Las preferencias y la demanda son consideradas suficientes para el propósito de gran parte de la teoría económica positiva y normativa, dicen Doyal y Gough (1991) basándose en Penz? La economía

\footnotetext{
${ }^{7}$ Más adelante en esta misma sección muestro que ésta es sólo una impresión y que, cuando se analiza a fondo, la teoría neoclásica del
} 
ortodoxa del bienestar (una rama de la teoría neoclásica del consumidor, TNC), continúan, enuncia dos principios: 1) la concepción subjetiva de los intereses: los individuos son las únicas autoridades a propósito de lo correcto de sus intereses o apetencias (wants);2) el de la soberanía del consumidor: la producción debe ser determinada por las preferencias individuales ${ }^{8}$. La teoría, una vez que abandonó la medición directa de la utilidad y que se basa ahora en la satisfacción de apetencias, está a un paso de la igualación entre bien-estar y opulencia (ingreso real) ${ }^{9}$, sosteniendo que la satisfacción subjetiva de apetencias puede ser medida científicamente y usada para evaluar situaciones o políticas.

La idea que los individuos son la única autoridad para juzgar lo correcto de sus apetencias, continúan Doyal y Gough, queda severamente en duda una vez que se admiten límites a los conocimientos y la racionalidad. 'Apetencias basadas en la ignorancia son epistémicamente irracionales' dice G. Peter Penz. Pero la crítica más demoledora de Penz es la de la 'evaluación circular': las apetencias son moldeadas por las mismas instituciones y procesos que han de ser evaluados en función de la satisfacción de dichas apetencias (Penz, 1986: 87). Del catálogo de problemas e inconsistencias de la TNC, Penz deriva dos conclusiones adicionales que complementan lo dicho antes:

Primero, que la satisfacción de apetencias es un principio que no puede hacerse mensurable sin juicios normativos adicionales ${ }^{10}$. Segundo, de desarrollarse tales juicios normativos externos, su inserción en el principio de satisfacción de apetencias subvierte el carácter abierto y subjetivo del principio. Sin embargo, no insertarlo lo deja abierto a problemas de ignorancia e irracionalidad, de evaluación cir-

consumidor requiere de las necesidades y las cuela subrepticiamente en su análisis.

${ }^{8}$ Esta visión es ingenua y contrasta agudamente con la concepción marxista de las relaciones entre producción y necesidades. (Véase el cap. 9 de Ampliar la mirada para la visión al respecto de Marx en la Introducción a la crítica de la economía política (1857), así como la de J. P. Terrail que profundiza en dicha visión.)

${ }^{9}$ Como veremos en la sección 6 , sin el "a un paso", esto es lo que hacen los economistas ortodoxos cuando estudian la pobreza: en los hechos igualan utilidad con opulencia o ingreso real de las personas.

${ }^{10}$ Esto lo admite de manera muy explícita Ravallion, como veremos en la sección 6 . cular y de no comparabilidad. Este dilema refleja la quintaesencia de las limitaciones del principio de satisfacción de apetencias. (Penz, 1986: 132 y 136; citado por Doyal y Gough, 1991: 24) ${ }^{11}$.

Analizaré, en el texto que sigue, la teoría neoclásica del consumidor (TNC), basándome en Bryant (1990) y Deaton y Muellbauer (1991 [1980]), obras especializadas en el tema. Mostraré que la TNC: 1) se deshace del concepto de necesidad de manera ambigua, ya que éste vuelve a entrar por la puerta trasera (o delantera); y 2) no resiste la introducción de necesidades humanas y de umbrales de pobreza en sus elaboraciones más básicas.

En la TNC "la demanda de bienes y servicios es el resultado de la interacción entre las preferencias del hogar, sintetizadas en una función utilidad" (Bryant, 1990: 17), "sus posibilidades, representadas por la restricción presupuestal" y "un supuesto o hipótesis de conducta: que los hogares intentan maximizar la satisfacción o el bienestar" (ibid.: 18 y 27, cursivas añadidas). Una vez que estos tres elementos se ponen juntos la solución óptima de la que se derivan las ecuaciones de demanda se sigue algebraicamente.

Deaton y Mullbauer definen un conjunto de axiomas de la elección (de compra de bienes y servicios), la "aceptación de los cuales es equivalente a la existencia de una función de utilidad" (1991 [1980]: 26-30). Los axiomas son: 1) Reflexividad. Toda canasta de bienes es al menos tan buena como ella misma. 2) Completitud. "Este axioma dice que cualesquiera dos canastas pueden ser comparadas, que el consumidor puede juzgar entre cualquier par de canastas de bienes". 3) Transitividad o consistencia. Si la canasta $a$ se prefiere a la $b$ y la $b$ a la $c$, la $a$ debe preferirse a la $c$. 4) Continuidad, cuyo significado coincide con la comprensión intuitiva de esta palabra. 5) No saciedad. La función de utilidad es no decreciente en cada uno de sus argumentos (bienes), y es creciente en al menos un argu-

\footnotetext{
${ }^{11}$ Este dilema afecta también al enfoque de capabilities de Sen, como se desprende de las críticas que se presentan en la sección 5 infra. Su enfoque perdería su carácter abierto y pluralista si introdujera en su esquema juicios normativos externos. Pero al no hacerlo, su planteamiento queda como un enfoque no operacional y estéril.
} 
mento. 6) Convexidad, cuyo sentido se entiende geométricamente de manera intuitiva. Estos axiomas, la restricción lineal del presupuesto y la maximización de la utilidad proveen la solución.

En la exposición formal de la TNC las necesidades no aparecen por ninguna parte. Y sin embargo, como veremos, están por todos lados. En el capítulo 1, llamado "Límites de la elección", Deaton y Mullbauer (1991 [1980]: 3 , cursivas añadidas) señalan:

El énfasis se suele situar en las preferencias, en los axiomas de la elección, en las funciones de utilidad y sus propiedades. La especificación de cuáles elecciones están realmente disponibles recibe un lugar secundario [...] A diferencia de las preferencias, las oportunidades para la elección son observables directamente [...] Es nuestra opinión que mucho puede ser explicado [...] [por las oportunidades], y que el papel de las preferencias tiende a sobreestimarse.

En el primer diagrama incluyen, además de la restricción presupuestaria, por primera y única vez en todo el libro, la "restricción de sobrevivencia". En los ejes miden cantidades de alimentos y alojamiento, para cada uno de lo cuales indican el mínimo de sobrevivencia que configuran el punto A. Concluyen que, al introducir esta restricción adicional, la elección queda reducida a la parte del espacio situada por arriba y a la derecha de A, y que los hogares con un presupuesto que sólo permita adquirir los mínimos tendrán que hacerlo así o dejar de existir (1991 [1980]: 4-5). Introducir una restricción de sobrevivencia equivale a introducir las necesidades humanas y la pobreza ${ }^{12}$. Pero la actitud ambigua de los autores se refleja en que en lugar de asumir plenamente la restricción de sobrevivencia la presentan como una contingencia: "si hay restricción de sobrevivencia", dicen. La presencia de esta restricción reforzaría mucho las conclusiones del párrafo citado supra. Cuando las restricciones del presupues-

\footnotetext{
${ }^{12}$ Es evidente que Deaton y Mullbauer han enunciado, sin darse cuenta, una definición del umbral de pobreza extrema como la situación en la cual se puede sobrevivir pero donde no hay elección (en la que se igualan las dos restricciones, la de las necesidades y la del presupuesto). El lector es remitido al cap. 1 de Ampliar la mirada, en el que muestro un concepto de necesidad que es, justamente, la ausencia de libertad y de elección.
}

to $y$ de sobrevivencia dejan al consumidor con cero grados de elección, las preferencias se vuelven inaplicables o irrelevantes. Es evidente que la teoría del consumidor basada en las preferencias tiene que revisarse. Pero aún más importante por su generalidad, para los consumidores no pobres, para los cuales por definición el presupuesto es mayor que el mínimo requerido, sólo sobre el excedente hay, en algún sentido, libertad de elección ${ }^{13}$. A pesar de lo precedente, que apuntaría al reconocimiento de las necesidades, los autores mantienen que la cantidad demandada de un bien depende sólo de los precios y de la restricción presupuestaria, negando de nuevo las necesidades humanas.

Cuando los autores introducen las curvas de Engel (que muestran las proporciones del gasto que los consumidores destinan a un grupo de bienes) y señalan que sirven para identificar los bienes necesarios o básicos y distinguirlos de los de lujo, introducen lo necesario como atributo de los bienes cuando los individuos han sido definidos como libres de necesidades, configurando un caso notable de fetichismo de las mercancías, ya que éstas asumen cualidades de las cuales se ha despojado a los seres humanos. Por su carácter formal vacío y su rechazo a las necesidades, la TNC no puede predecir, ni explicar, regularidad estadística alguna en la conducta del consumidor ${ }^{14}$.

Los autores se preguntan (1991 [1980]: 21) si las preferencias son un elemento crucial en la descripción de la conducta del consumidor y responden que "probablemente no". Añaden: "la presencia de indivisibilidades, quiebres y otras no linealidades puede limitar la elección al grado que se requieran supuestos adicionales muy suaves para describir la conducta completamente" (cursivas añadidas). Desde luego, Deaton y Mullbauer, a pesar de esta conciencia, defienden la TNC.

\footnotetext{
${ }^{13}$ Cuando se introduce (lo que es ineludible) la interdependencia de los consumidores y, con ella, los patrones de consumo por clase y estrato social, incluso esta libertad de elección queda muy reducida, sino eliminada.

14 Algunas leyes de la conducta del consumidor que han sido verificadas en todo el mundo, como la participación decreciente del gasto en alimentos en el gasto de consumo total de los hogares a medida que éste aumenta, conocida como la Ley de Engel, dejan muda a la TNC. Lo peor de todo es que estas regularidades estadísticas no sirven para retroalimentarla, ya que ésta es absolutamente deductiva.
} 


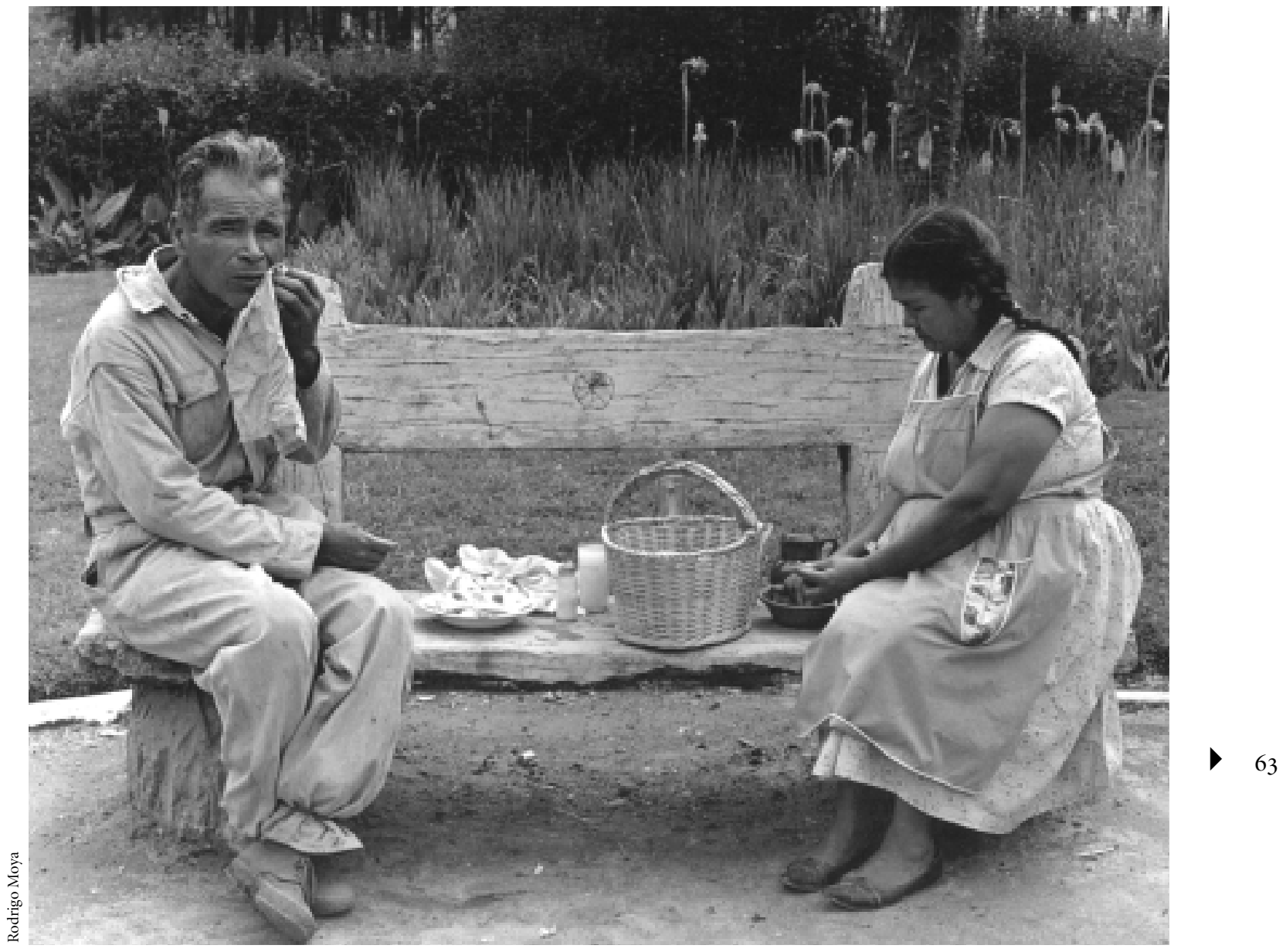

Parque Hundido, ciudad de México, ca. 1958.

Otros ejemplos de cómo las necesidades se cuelan por la puerta de atrás en la exposición de los autores se explican en el capítulo 10 de Ampliar la mirada. Pero refirámonos a uno en el que las necesidades entran por la puerta delantera. Para comparar niveles de bienestar entre hogares de diferentes tamaños y estructuras demográficas (mediante las llamadas escalas de equivalencia) acuden abiertamente a las necesidades humanas:

Las escalas de equivalencia se basan en el supuesto de que la única diferencia en gustos entre los hogares se debe a características observables [...] En muchos contextos es importante saber qué tan opulentos son los miembros de un hogar en comparación con los de otro hogar [...] Una manera es computando y comparando los presupuestos per capita [...] Sin embargo, esto ignora la variación en las necesidades de acuerdo con la edad: los bebés necesitan menos que los adultos [...]. Las escalas de equivalencia son deflactores [...] por medio de los cuales los presupuestos de diferentes tipos de hogares pueden ser transformados a una base necesidadcorregida (Deaton y Mullbauer, 1991 [1980]: 192, cursivas añadidas).

Ignorar las variaciones de las necesidades de acuerdo con la edad no puede estar mal si al mismo tiempo está bien ignorar, en todo el desarrollo de la teoría, las necesidades humanas. Pero la introducción subrepticia de conceptos de necesidades en medio del discurso neoclásico no es ex- 
clusiva de Deaton y Mullbauer. Es un 'fenómeno' inevitable. En el capítulo 10 de Ampliar la mirada muestro cómo se manifiesta en Bryant, quien al caracterizar a los hogares hace notar que "sin elección, la unidad no puede perseguir su propio bienestar y, por tanto, no se puede calificar como una conducta orientada a objetivos". Bryant suele ilustrar las curvas de indiferencia ubicando en un eje alimentos y, en el otro, todos los demás bienes. En ese contexto muestra una de las inconsistencias del axioma de la no saciedad y trata sin éxito, lo que no muestro en la cita, de salir del problema en que se ha metido:

[...] se supone que el hogar prefiere más que menos: más alimento, más de 'todos los demás bienes'. Se puede argumentar correctamente contra este supuesto, ya que hay muchas cosas en montos mayores a cierto límite, incluyendo alimento, que la familia prefiere menos que más (Bryant, 1990: 17-18).

Lo que acaba de aceptar, que la no saciedad es falsa, que muchas necesidades humanas tienen límites absolutos, derrumba la TNC. Esta restricción "por arriba" llevó a los teóricos originales de la TNC a concluir no sólo que los bienes específicos tienen una utilidad marginal decreciente, sino también el dinero, de lo cual derivaban conclusiones igualitaristas. Bryant dice que un hogar está en equilibrio "cuando no tiene incentivos para cambiar sus patrones de gasto" (1990: 30). Los pobres no pueden estar nunca en equilibrio. La TNC no puede decir nada sobre su conducta.

Deaton y Mullbauer, al analizar la evidencia asociada a cuatro modelos empíricos desarrollados a partir de la teoría, concluyen que: a) "Los modelos producen un conflicto con la teoría. Las restricciones de homogeneidad y simetría, básicas para el supuesto de una restricción presupuestal lineal $y$ para los axiomas de la elección, son consistentemente rechazados por la evidencia". b) "Hay otras importantes variables explicativas distintas que los precios y el gasto total" (1991 [1980]: 79-80)). Es decir, existen variables omitidas. Estas conclusiones desfavorables para la TNC los obligan a caer en el síndrome de la inconsistencia ${ }^{15}$ : "No creemos que [...] sea necesario abandonar

15 Éste es un síndrome usual entre quienes son llevados a algo por impulsos ajenos a la racionalidad del asunto en cuestión. En este caso, los axiomas de la elección a la luz de los resultados de este capítulo. En última instancia, desde luego, dada suficiente evidencia convincente, debemos estar preparados para hacerlo" (idem: 82).

Cuando se reconoce que el consumidor no es un robot sino un ser biológico y social y se introducen explícitamente las necesidades humanas, la cantidad demandada por un individuo/hogar de un bien específico dependerá ya no sólo de su presupuesto y del precio, sino también de los requerimientos ineludibles del mismo (que pueden ser cero o valores positivos). Podemos expresar, por tanto, el presupuesto total $\left(\mathrm{x}_{\mathrm{T}}\right)$ como la suma del presupuesto necesario $\left(\mathrm{x}_{\mathrm{N}}\right)$ y el presupuesto libre $\left(\mathrm{x}_{\mathrm{L}}\right)$. Al aumentar el precio de uno o varios bienes básicos disminuye en términos reales $\mathrm{x}_{\mathrm{T}} \mathrm{y}$, como el consumidor mantendrá el nivel de $\mathrm{x}_{\mathrm{N}}$ sin cambio mientras sea posible, disminuirá $\mathrm{x}_{\mathrm{L}}$. La cantidad demandada de cada bien básico será una constante en relación con sus propios precios en todos los hogares en los cuales $\mathrm{x}_{\mathrm{T}}$ sea mayor o igual que $\mathrm{x}_{\mathrm{N}}$. En cambio, la cantidad demandada de los bienes no básicos descenderá cuando aumentan los precios de ambos tipos de bienes.

Veamos qué pasa con los axiomas 2, 'completitud', 3, 'transitividad' y 5 , 'no saciedad', al introducir necesidades humanas (la restricción de sobrevivencia). Empecemos identificando las necesidades nutricionales de un varón adulto con valores promedio de peso, talla y tipo de actividad entre 2660 y 2940 kilocalorías y entre 57 y 63 gramos de proteína ideal. En esos rangos, nuestro varón adulto se encuentra en la situación ideal. Por debajo de ambos límites mínimos se presentaría la desnutrición; por arriba de los máximos, la obesidad. Por tanto, desde el punto de vista de las proteínas y calorías, los consumidores tienen muy poco margen de elección que les permita conservarse en un óptimo objetivo (distinto del óptimo subjetivo de la teoría neoclásica). Esto es consistente con el "modelo de la vitamina" (Warr, 1987) que sostiene que, a medida que aumenta la cantidad de una característica a la que tiene acceso una persona, el bienestar aumenta al principio hasta llegar a un nivel, después del cual el bie-

el impulso puede ser la necesidad de pertenencia al club del mainstream economics. 
nestar permanece constante aunque continúe aumentando la cantidad de la característica y, finalmente, si continuamos aumentando ésta, el bienestar empezará a descender. Esto conforma una curva de bienestar en forma de montaña. Aunque quizás este modelo, que refuta el axioma de la no saciedad (a partir de ciertos niveles de presencia de las características, las funciones de bienestar objetivo son decrecientes en el argumento respectivo), no sea aplicable a todas las necesidades humanas (es posible que la educación sea una de las excepciones), intuitivamente parece aplicable no sólo a alimentación sino a muchas otras necesidades.

Para que el axioma de completitud sea válido en niveles de ingresos inferiores a los requerimientos mínimos, los hogares tendrían que ser capaces de ordenar, de mejor a peor, diversas canastas que dejan una o más necesidad(es) insatisfecha(s). Un ejemplo de las terribles opciones que el consumidor 'racional' tendría que ordenar puede ser: por un lado, una canasta que deja a la mitad la compra de alimentos pero que incluye la insulina del jefe del hogar, vis à vis una que cubre los requerimientos nutricionales del hogar, pero que no incluye la insulina. En la primera opción, los miembros del hogar bajarán de peso y pueden morir por enfermedades dada su débil resistencia, y tiempo después morirán por inanición. En la segunda, el jefe del hogar estará muerto muy pronto. El axioma no tiene sentido. Nadie puede tener la experiencia previa para poder hacer una evaluación así. Cualquiera que sea la 'decisión' provisional que tomen, entrarán en un estado de desequilibrio agudo, opuesto al mundo feliz de los óptimos y los equilibrios de la TNC. El axioma de completitud no aplica por debajo de los umbrales de pobreza.

Igualmente inválido resulta el axioma de transitividad. Para apreciarlo, adicionemos una tercera opción al ejemplo previo. Supongamos que el hogar puede aliviar su escasez de recursos si la hija adolescente entra a trabajar a un burdel. Como esta opción no ha sido adoptada hasta hoy, la TNC indicaría que es la menos preferida (la opción c del axioma de transitividad). Sin embargo, en el periodo siguiente, después de una crisis diabética del jefe, la adolescente puede decidir trabajar en el burdel. La menos preferida puede terminar siendo la opción elegida. Las ordenaciones no son transitivas.
Igualmente, mirando a la clase alta podemos preguntarnos cómo puede saber un millonario que nunca ha tenido un yate si prefiere el yate a una nueva casa de campo. Este tipo de decisiones, tanto en la cúspide como en el sótano de la sociedad, se toman sin experiencia previa, de tal modo que no hay manera en que los consumidores puedan saber lo que significarán. La clase media, situada por arriba de los mínimos, pero con restricciones de recursos, es la única candidata a actuar según un modelo de optimización al consumir. Pero la interdependencia entre los consumidores lleva a plantear la hipótesis de que las elecciones, más que individuales/familiares, terminan siendo del estrato/clase en su conjunto, por la presión para vivir como los demás. Así, la inmensa mayoría de los hogares de estos estratos terminan adoptando el mismo estilo de vida y asignando de manera muy similar su ingreso.

En síntesis, en lo dicho he mostrado que los axiomas de completitud, transitividad y no saciedad no aplican en condiciones de pobreza y que el ejercicio de optimización no tiene sentido para los hogares de clase alta que, por definición, no necesitan optimizar a causa de su holgura de recursos. Los axiomas invalidados son determinantes en la TNC. Sin ellos, la teoría se colapsa. Otra manera de expresar esta conclusión es que la TNC podría ser válida para seres sin necesidades, para robots, pero no lo es para seres biológicos, necesitantes. En Ampliar la mirada avanzo un poco en la formulación de una teoría alternativa basada en la jerarquía de necesidades.

\section{LOS ENFOQUES DE LAS CAPABILITIES DE SEN Y NUSSBAUM}

Una vez que las críticas de Sen y Rawls, y la presentada en la sección anterior, derrotan al utilitarismo y a la TNC, parecería que el enfoque de las capabilities y los functionings de Sen (EC) muestra el camino correcto. Dado que capabilities parece un concepto igual a capacidades, y en mi respuesta tentativa había incorporado capacidades al lado de las necesidades para conformar el elemento constitutivo del eje de florecimiento humano (EFH), parecería redundante mi nuevo enfoque. Para poder sustentar su necesidad, resultó indispensable deslindarlo del 


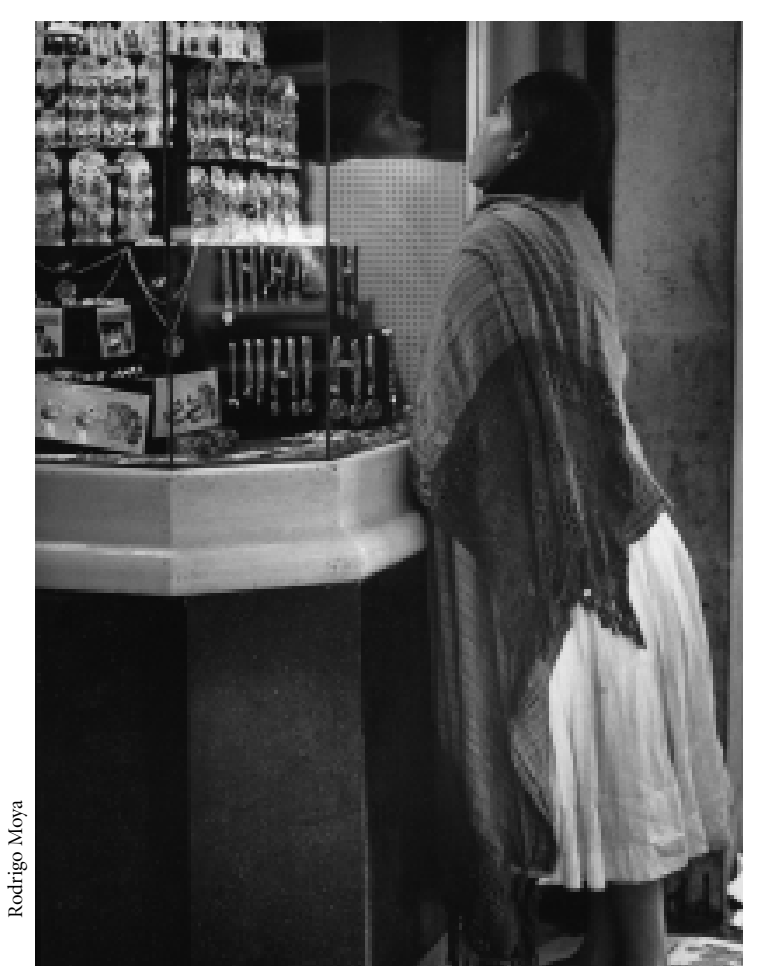

Centro de la ciudad de México, ca. 1958.

EC de Sen así como explorar el EC de Martha Nussbaum que da una respuesta (en apariencia) similar a la de Sen. Las conclusiones a las que llego en Ampliar la mirada, por lo que se refiere al EC de Sen, son: 1) no considera la unidad necesidades-capacidades como elemento constitutivo del EFH; 2) aborda directa y exclusivamente el eje del nivel de vida porque sólo considera los functionings asociados al uso de bienes y servicios; 3 ) sólo considera las capabilities asociadas al poder de compra y no las capacidades humanas como tales.

A continuación sintetizo mis críticas y las de otros autores al EC de Sen. Bernard Williams (1987) le señaló a Sen, en esencia, que su teoría está vacía, que es necesario especificarla (definiendo un conjunto de capabilities básicas correalizables, lo que ha hecho Nussbaum pero no Sen) y fundamentarla mediante teorías sobre la naturaleza humana y las convenciones sociales (lo que no ha hecho Sen y que Nussbaum sostiene haber hecho basada en Aristóteles y en Marx). Además, mostró que no todas las capabilities tienen que ver con la elección, poniendo en duda la asociación entre capability y libertad (de elección), central en el EC.

Gerald A. Cohen (1993) dice que Sen logró una revolución conceptual al introducir dos cambios de enfoque: del estado real a la oportunidad, y de los bienes (y la utilidad) a los functionings, pero que su exposición padece de una oscuridad discursiva severa, que se explica por el uso de la palabra capability para describir tanto lo que la persona es capaz de hacer, como lo que los bienes hacen por ella, y para lo segundo la palabra capability resulta inadecuada. Cohen destaca el lado pasivo del ser humano que el EC parece olvidar totalmente y critica la insistencia de Sen en presentar el elemento constitutivo como lo que alguien logra hacer o ser porque el tipo de vida que alguien lleva no puede identificarse sólo con logros, ya que hay muchos beneficios que los individuos no logran (como no padecer paludismo). Hace notar que el resultado de comer la comida es la capacidad de realizar actividades valiosas, pero que ésta no es la capability que Sen asocia con la comida sino la de estar bien nutrido y entretener a amigos. Critica a Sen por darle un carácter atlético al término capability, lo que en mi opinión es resultado del intento de Sen de convertir las necesidades en capabilities, para lo que se requiere que sea la persona el sujeto activo. Al final, Cohen parece aceptar functioning como dimensiones del hacer y del ser/estar, pero rechaza la centralidad de la expresión "habilidad de lograr" que deja fuera la parte pasiva del ser humano y sobreestima el papel de la libertad y la actividad en el bien-estar. Sen ha hecho caso omiso de las críticas de Williams y de Cohen, dando la impresión de que mira a los demás como implementadores del nuevo e inexpugnable paradigma.

John Rawls también ha hecho una poderosa crítica al EC de Sen. El propio Sen relata que aquél considera que si los individuos tienen objetivos distintos las tasas de conversión de bienes primarios a capabilities no pueden ser comparadas, lo que implicaría, añade, que tal como está formulado el EC no tiene base de sustento. Esto es muy grave porque el supuesto de Sen de que cada persona elige su propio conjunto de capabilities implica que no hay dos conjuntos iguales. Los ejemplos de Sen sobre las diferentes tasas de conversión de bienes a functionings se basan 
siempre en los mismos functionings (como estar bien nutrido) entre diversas personas. La crítica de Rawls se puede traducir en preguntas como: ¿Es posible decir que la tasa de conversión de pan en nutrición de Antonio es menor que la de ingresos en autoestima de Pedro? En el capítulo 7 de Ampliar la mirada analizo en detalle el intento de Sen, infructuoso en mi opinión, de demostrar que tal comparación sí es posible.

Frances Stewart (1996) identifica dos problemas del EC: 1) El carácter inobservable del capability set, que deja como única opción la evaluación de los functionings. 2) $\mathrm{Al}$ no incorporar valoración alguna, el EC es incapaz de ordenar dos conjuntos de consumo para la misma persona, lo que coincide con la crítica de Crocker (1995) de que el EC no es capaz de categorizar ninguna capability como no valiosa ni distinguirlas de las perniciosas. En sentido asociado, Des Gasper (2004) ironiza que en el EC la clave sea lo que la 'gente tiene razón para valorar', por lo cual "interpretaríamos que el consumidor inmovilizado frente a la TV por seis horas diarias representa una realización de la libertad razonada".

Sabina Alkire (2002) ha defendido a Sen de las críticas sobre la no operacionalidad del EC al señalar que su carácter abierto explica que no haya una única manera de operacionalizarlo, pero que en cada aplicación concreta se puede hacer, consagrando así la renuncia de los teóricos a teorizar.

En sus esfuerzos de implementación del EC, tanto Alkire (2002) ("una capability básica es una capability para satisfacer una necesidad básica”) como Meghnad Desai (1994), quien para derivar requerimientos de bienes y servicios de su lista de cinco capabilities básicas para la medición de la pobreza, encuentra que necesita introducir como nivel intermedio las necesidades, ponen de relieve la dependencia del EC del concepto de necesidad, mostrando que el EC no puede constituirse en un enfoque independiente. Algo similar ocurre con el EC de Martha Nussbaum. Sin embargo, cuando Alkire se percata de la diferencia entre necesitar, que no es un verbo intencional, y la elección de la capability que sí lo es, descubre la eliminación del reino de la necesidad en el EC: que el cambio de necesidad a capability hace desaparecer las diferencias entre el alimento y el teñirse el pelo de azul.
Apoyándome en la formalización (que tiene la ventaja de la precisión) del EC que Sen presenta en Commodities and Capabalities (1985), muestro que se trata de un enfoque mecanicista. De la primera ecuación que en dicho libro presenta se desprende que los functionings que una persona alcanza son sólo función de su ingreso (o titularidades) y de las características personales que gobiernan la transformación de bienes en functionings, siendo este segundo elemento el único que lo distingue de los enfoques que miden el bien-estar a partir de los ingresos. Sen además introduce ecuaciones de evaluación subjetivas (individuales) de los functionings que reemplazan las funciones de utilidad. Al hacerlo, cae en tres vicios que comparte con el utilitarismo (y el segundo él mismo lo ha criticado): 1) la función introducida es un mero artificio y la evaluación termina llevándose a cabo sólo con el ingreso; 2) así como los pobres resignados son muy eficientes convertidores de acceso a bienes en utilidad, valoran más alto que un depauperado ex miembro de la clase media el mismo conjunto de functionings; y 3 ) no elimina ni los gustos caros ni los gustos ofensivos.

Como se ve, el EC de Sen es subjetivista y mecanicista y puede conducir a resultados inaceptables, en los cuales el único satisfactor son los bienes y servicios, rasgo que comparte con el enfoque más convencional de la EPP. En él no caben capacidades como la de "sentidos, imaginación y pensamiento" de Nussbaum, ni las que Gasper llama S-capabilities (S por skill), sino sólo la que este autor llama O-capabilities (O por oportunidad). Sen concibe la capability como algo que se deriva de la posesión de bienes, como capability económica. Es una concepción alienada de las capacidades humanas, en la que la única capacidad es la de poseer mercancías. Al no plantear una ley de rendimientos decrecientes del ingreso en términos de functionings y capabilities, queda implícito que a mayor ingreso mayores capabilities, valorando el consumo superfluo y justificando así la desigualdad (a pesar de sus importantes escritos sobre el tema).

Para Sen lo valioso es el bienestar de libertad: la libertad de elección entre conjuntos viables de functionings, o capability set, cuya amplitud está determinada por las titularidades (o ingreso). El EC queda intencionalmente incompleto porque, en su afán por estar dentro de la 'eco- 
nomía de la corriente principal', Sen necesita operar con la lógica de las preferencias, de la cual se saldría si formulase una lista de capabilities básicas. Por ello Sen habla siempre de elección entre estados del ser y del hacer que el individuo considera valiosos, no que son valiosos de acuerdo con algún criterio externo, por lo cual le son aplicables algunas de las críticas de Penz a la TNC. Como en la TNC, para Sen lo que elige el individuo siempre será óptimo. Así sea ver seis horas diarias TV o torturar a su prójimo.

Algunos autores creen que el EC es muy amplio. Pero como se muestra siguiendo las ecuaciones en Commodities and Capabilities, Sen va mecánicamente de los bienes a los functionings y a la capability. Su universo se reduce a lo que se deriva del consumo de bienes, pero excluye satisfactores como relaciones y actividades. Es una visión de la persona como consumidor (lo contrario de lo que piensa Cohen), pero que parece activo porque Sen le endilga verbos.

Sen no busca fundamentar su concepción en la esencia humana, ni apoyarse en teorías sobre las necesidades, porque no lo necesita. Su EC no ha sido operacionalizanes de ningún tipo. A pesar de ello, Sen sugiere que se puede evaluar en dos espacios: los functionings alcanzados y la libertad (medida quizás como grado de libertad o amplitud del capability set). En ambos casos, el resultado dependería centralmente del conjunto de titularidades (o del ingreso) y marginalmente de los parámetros de conversión de recursos en functionings. En ausencia de información individual de estos parámetros, la ordenación sería la derivada de las titularidades (o del ingreso).

Martha Nussbaum identifica las siguientes semejanzas y divergencias entre su versión del EC y la de Sen: 1) Define una lista de capabilities humanas centrales y un umbral en cada capacidad (y él no). 2) Sen nunca ha intentado fundamentar el EC en la idea marxista/aristotélica del funcionamiento verdaderamente humano que desempeña un papel central en el enfoque de Nussbaum. 3) La distinción de tres tipos de capacidades ${ }^{16}$ que ella

16 Martha Nussbaum se refiere a capacidades en el sentido usual del término, al menos parcialmente, por lo cual en este caso he traducido capabilities como capacidades. hace, añade Nussbaum, no tiene paralelo en Sen: a) capacidades básicas (habla, amor y gratitud, razón práctica y la capacidad de trabajar), que son innatas; b) capacidades internas, que son estados desarrollados de la persona; c) capacidades combinadas, definidas como las capacidades internas combinadas con condiciones externas.

Detrás de la identificación de ciertas capacidades centrales y de un umbral básico en cada capability están las siguientes ideas intuitivas, argumenta Nussbaum: 1) que ciertas funciones son centrales en la vida humana en el sentido de que sin ellas no hay vida humana; y 2) que hay una manera verdaderamente humana (no sólo animal) de llevar a cabo estas funciones. La idea central, continúa Nussbaum, es la de un ser humano como un ser libre y dignificado que moldea su propia vida por medio de los poderes de razón práctica y sociabilidad en cooperación y reciprocidad con otros. El planteamiento se separa radicalmente del de Sen y se asemeja al adoptado en Ampliar la mirada. Sin embargo, es ingenuo en la medida en la que no está problematizado, por ejemplo, con la noción de la alienación.

La lista de capabilities combinadas que formula Nussbaum identifica las capabilities de importancia central en cualquier vida humana, dejando espacio para un pluralismo razonable de especificación ${ }^{17}$. Es una lista de componentes separados (correalizables). Todas son de central importancia y de calidades distintas, lo que limita las compensaciones. Cualquier situación debajo del umbral en cualquier capability es trágica. Cuando dice que ciertas habilidades humanas ejercen la reivindicación moral que deben ser desarrolladas, Nussbaum atribuye una fuerza moral a las capabilities que corresponde sólo a las necesidades humanas, como lo han mostrado Wiggins (2002 [1987]) y Doyal y Gough (1991). Cuando las capabilities básicas se ven privadas de la nutrición (satisfacción de las necesidades, incluyendo educación) que las transformaría en capabilities combinadas, se vuelven estériles. Nuss-

\footnotetext{
${ }^{17}$ La lista, muy simplificada, de capabilities combinadas es: 1) vida;2) salud corporal (incluye alojamiento adecuado); 3) integridad corporal (incluye oportunidades reproductivas y de satisfacción sexual); 4) sentidos, imaginación y pensamiento (incluye experiencias placenteras); 5) emociones; 6) razón práctica;7) afiliación; 8) otras especies; 9) juego; 10) control sobre su medio ambiente.
} 
baum señala que el florecimiento es el desarrollo de las potencialidades humanas, y la pobreza su negación.

Como se aprecia, hay una enorme cercanía entre las ideas de esta autora y las tesis centrales de Ampliar la mirada. Sin embargo, una parte importante de los elementos de la lista son sólo re-fraseos de necesidades humanas (lo cual es muy obvio en: "ser capaz de estar bien nutrido", "ser capaz de tener alojamiento adecuado"), lo que los descalifica como capacidades humanas. Otros se refieren a auténticas capacidades humanas. Algunas capacidades no son combinadas ("ser capaz de tener propiedad inmobiliaria y mobiliaria”), ya que no constituyen atributos de la persona. Esto muestra que el intento por reducir a una categoría única todos los rasgos de la buena vida es inevitablemente fallido y que necesitamos, al menos, hablar de necesidades desarrolladas y satisfechas, capacidades desarrolladas y aplicadas, libertades negativas, derechos y oportunidades, si queremos entender, medir y promover el florecimiento humano.

\section{CRÍTICA DE LAS DEFINICIONES DE POBREZA DOMINANTES EN LA EPP}

En la sección 7 examino la concepción de necesidades, satisfactores y recursos predominante en la economía política de la pobreza (EPP) de manera general, sin referirme a autores específicos, con el propósito de mostrar las implicaciones que tiene abordar el eje del nivel de vida (ENV) de manera directa, sin pasar por el de florecimiento humano (EFH), lo que he llamado la tesis crítica. Las conclusiones de esta sección, en la que examino las definiciones de pobreza de un grupo de autores, sustenta las generalizaciones a las que llego en la siguiente. Sin embargo, y en contraste, al entrar al análisis de las definiciones específicas perdemos el detalle fino de los recursos principales y secundarios, perdemos totalmente la dimensión de satisfactores, y nos quedamos sin un esquema explícito de las necesidades humanas. Ambas secciones deben verse conjuntamente como elemento central de la crítica de la EPP.

Pobreza es, dice el Diccionario de la Real Academia Española (DRAE): "carencia de lo necesario para el sustento de la vida". Las diez definiciones de pobreza analizadas en el cuadro 1 (pp. 70-71) las he homologado a la estructura básica del DRAE, identificando en qué términos definen "lo necesario" (los medios) y cómo completan la frase que empieza con "para" (el propósito). Al hacerlo se precisa cómo definen el objeto de estudio de la pobre$\mathrm{za}^{18}$. En la primera columna se presentan las definiciones textuales de los autores; en la segunda se reformulan de manera homologada con la definición del DRAE, y en la última columna se añaden algunas observaciones. Las definiciones de pobreza incluidas se han clasificado, en primer lugar, en dos grupos: 1) las que incorporan el concepto de necesidad, y 2) las que se basan en conceptos distintos (rechacen o no explícitamente el concepto de necesidades). El primer grupo incluye la definición de Altimir, la primera de Sen y Foster, y las tres de Boltvinik (definiciones 1 a 5 del cuadro). Las tres primeras podemos clasificarlas como parte del enfoque convencional de necesidades de la pobreza; las dos últimas corresponden al desarrollado en Ampliar la mirada. El segundo grupo, que comprende también cinco definiciones (6 a 10 del cuadro), se puede dividir, a su vez, en dos subgrupos: la de Townsend y la segunda de Sen-Foster (6 y 7), que podemos calificar como búsquedas fallidas de un nuevo enfoque y el enfoque economicista dominante (definiciones 8 a 10). Los grupos y subgrupos formados no son homogéneos: hay grandes diferencias en su interior. El enfoque convencional de necesidades, las búsquedas fallidas de un nuevo enfoque y el enfoque economicista dominante conforman la EPP, objeto de la crítica de este artículo. Una manera ágil de comparar las definiciones es la lectura vertical de las definiciones homologadas en la segunda columna del cuadro.

De su definición textual podemos inferir que para Altimir (1979) la variable que ha de medirse es el bienestar, cuyo elemento constitutivo identifica como satisfacción de necesidades básicas. Sin embargo, acota doblemente el concepto de necesidades: son sólo las básicas (no todas las humanas) y no son todas las básicas, sino sólo algunas.

\footnotetext{
${ }^{18}$ Es algo similar a lo que ocurre en materia de desigualdad, en la que las diferentes teorías igualitaristas se distinguen por la manera en la que completan la frase "a cada quien según...".
} 
Cuadro 1. Comparación de algunas definiciones convencionales de

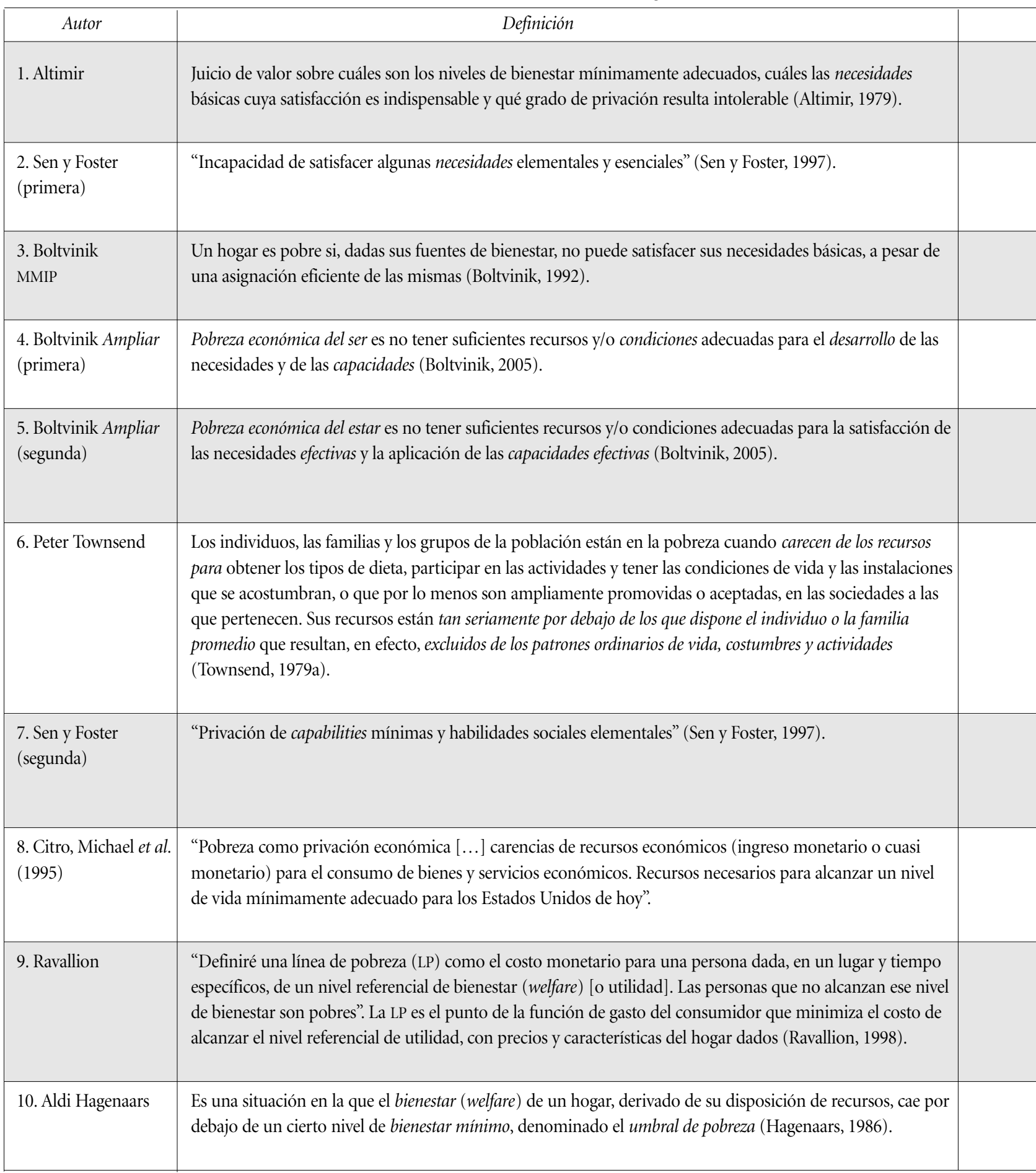


pobreza con las de pobreza económica del ser y del estar

\begin{tabular}{c|c}
\hline \multicolumn{1}{|c}{ Reformulación de la definición } \\
\hline $\begin{array}{l}\text { Carencia de... ingresos corrientes para... satisfacer algunas } \\
\text { necesidades básicas. }\end{array}$
\end{tabular}

Carencia de ingresos ajustados por la diversidad humana para.. satisfacer algunas necesidades elementales y esenciales.

Carencia de fuentes de bienestar para... satisfacer las necesidades básicas

Carencia de fuentes de bienestar y/o oportunidades para... el desarrollo de las necesidades y de las capacidades

Carencia de fuentes de bienestar y/o condiciones para... la satisfacción de necesidades efectivas y aplicación de capacidades efectivas.

Carencia de los recursos para... participar en los patrones ordinarios de vida, costumbres y actividades.

\section{Observaciones}

Algunas necesidades, pues pregunta cuáles deben satisfacerse. En la medición especifica lo necesario como ingresos y reduce las necesidades a la alimentaria. No precisa umbrales.

Las oportunidades reales que especifican lo necesario son ingresos ajustados para tomar en cuenta la diversidad humana. No precisan umbrales.

El MMIP es un método combinado (directo e indirecto). En cada dimensión directa se definen umbrales. El umbral de ingresos se basa en una canasta normativa completa.

Condiciones u oportunidades: de educación, de empleo que movilice y desarrolle capacidades, entorno cultural favorable al desarrollo de necesidades y capacidades.

Efectivas es igual a realmente desarrolladas por el individuo. Ésta y la definición previa tienen que aplicarse simultáneamente. De otra manera, quien necesita menos puede resultar menos pobre en el estar.

$\mathrm{Al}$ concebir las necesidades como variables entre sociedades, las sustituye por patrones de vida. El énfasis relativista en la diferencia respecto a los ingresos promedio convierte a éstos en la norma de referencia. Lo que es, en promedio, lo convierte en lo que debe ser para todos. A pesar de una amplia concepción de recursos, termina igualándolos a los ingresos. Insinúa umbrales (relativistas).

Ésta es su definición preferida. Capabilities es (casi) lo mismo que necesidades. Igual que en su primera definición, oportunidades se refiere a ingresos ajustados por la diversidad humana. No precisan umbrales.

"[...] enfocamos nuestro trabajo en la privación económica, definida de manera estrecha. Nos ocupamos del concepto, definición y medición de la pobreza económica, o lo que muchos llaman pobreza material". Precisan umbrales.

Ravallion admite que la teoría no ayuda a la definición de $\mathrm{U}_{\mathrm{Z}}$ y que la función de gastos requerida no puede identificarse a partir de la demanda observada de los consumidores.

Concluye que se necesitan juicios normativos externos (e información) para fijar la LP.

Las necesidades son sustituidas por la utilidad que "se puede medir con encuestas". Recursos se iguala a estatus económico. No precisa umbrales.
Carencia de lo necesario (recursos en sentido amplio) para... alcanzar un nivel de bienestar mínimo (utilidad). 
Es necesario ir al procedimiento de medición que adopta Altimir para precisar que identifica "un monto de ingresos corrientes del hogar" como "lo necesario", lo que implica un fuerte reduccionismo que comparte con otros autores incluidos en el cuadro ${ }^{19}$. Así, su definición homologada es: "carencia de ingresos para satisfacer algunas necesidades básicas". No obstante, en la medición, algunas necesidades se convierten sólo en la alimentaria ${ }^{20}$, mostrando otro reduccionismo. Pero su definición, al incorporar al menos una necesidad humana, no es tautológica como la de otros autores, según veremos.

La primera definición de Sen y Foster (1997) es casi igual a la de Altimir, excepto que en lugar de 'básicas' califican las necesidades como 'elementales y esenciales', las que, por la vía de los ejemplos, ilustran sólo con alimentos y alojamiento, dando a entender que, en efecto, están pensando en lo muy elemental y en lo muy esencial ${ }^{21}$. En cuanto al contenido de lo necesario, en apariencia se trata de oportunidades, pero al analizar éstas críticamente (deconstruirlas) resultan ser "ingresos ajustados para tomar en cuenta la diversidad humana" (véase columna de observaciones del cuadro 1), por lo cual es correcto interpretar esta definición como "carencia de ingresos ajustados por la diversidad humana para satisfacer algunas necesidades elementales y esenciales". La diversidad humana la toma en cuenta Altimir por la vía de requerimientos nutricionales variables según edad, sexo, ocupación, etc., haciendo más evidente la enorme similitud de ambas definiciones, que por ello he calificado como

\footnotetext{
${ }^{19}$ Sin embargo, en la conceptualización previa a la medición, Altimir tiene una mirada más amplia. En el capítulo 13 de Ampliar la mirada analizo con mucho mayor detalle las concepciones de pobreza de Altimir, Sen, Townsend y Hagernaars con base en diez rubros adicionales a la definición.

${ }^{20}$ Esto no es totalmente evidente. El método utilizado, el de la canasta normativa alimentaria (CNA), según he demostrado en diversas publicaciones (véase, por ejemplo, Boltvinik, 1999: 94-97) sólo identifica la pobreza alimentaria. Esta crítica se presenta también en la sección 15.3 de Ampliar la mirada. Por su parte, en las secciones 19.4 y 19.5 se analizan críticamente dos aplicaciones de tales variantes en México, el estudio INEGI-Cepal y el Método Oficial de Medición de la Pobreza de la Secretaría de Desarrollo Social del gobierno de Vicente Fox.

${ }^{21}$ Es notable que Sen, en 1997 (en esta obra con Foster), siga hablando de necesidades, ya que parecía haber sustituido este concepto por el de capabilities y functionings desde la primera mitad de la década de 1980.
}

enfoque convencional de las necesidades acotadas en el estudio de la pobreza.

La utilizada por Boltvinik en el MMIP (Método de Medición Integrada de la Pobreza), definición 3 del cuadro 1, "carencia de fuentes de bienestar para satisfacer las necesidades básicas" 22 , aunque muy similar a las anteriores tiene una mayor amplitud en dos dimensiones: todas las necesidades básicas contra algunas por el lado del propósito, y todas las fuentes de bienestar contra sólo una de ellas (el ingreso corriente) por el lado de los medios. La diferencia por el lado de los medios no es menor (involucra, entre otros, la incorporación, o no, del tiempo disponible y de los conocimientos y habilidades) y ha sido la base de la crítica interna más general que he desarrollado de los métodos parciales (a los que llamo así precisamente porque consideran sólo algunas fuentes de bienestar) que ordenan los hogares según el nivel de vida y, por tanto, miden mal la pobreza.

Dejo pendientes para el final las dos definiciones de pobreza económica asociadas al nuevo enfoque de la pobreza y el florecimiento humano desarrollado en $\mathrm{Am}$ pliar la mirada. Vayamos, pues, a los autores que sustituyen las necesidades por otros conceptos. Empecemos por Townsend y Sen, autores fundamentales en el tema y que no se caracterizan por un rechazo abierto al concepto de necesidades. En vez de ello, adoptan conceptos afines pero claramente distintos, aunque como veremos la sustitución de la palabra necesidades no es nunca inocente. Peter Townsend reemplaza 'satisfacer necesidades' con 'participar en los patrones ordinarios de vida (tipos de dieta, condiciones de vida e instalaciones), costumbres y actividades'. En la sección 7 argumento, con Wiggins, que el término necesidades no puede ser sustituido por deseos, apetencias o preferencias. ¿Podrá ser sustituido por la participación a la que se refiere Townsend? Veamos qué tanto se aleja su enfoque del concepto de necesidades. De los cinco elementos que constituyen el propósito (el para qué), los cuatro (excepto costumbres) que he resaltado con cursivas son satisfactores de las necesidades. Las costumbres dan lugar a actividades, a dietas, y quizás

\footnotetext{
${ }^{22}$ Hoy, a la luz de Ampliar la mirada, sustituiría básicas, que limita el
} universo de necesidades consideradas, por humanas. 


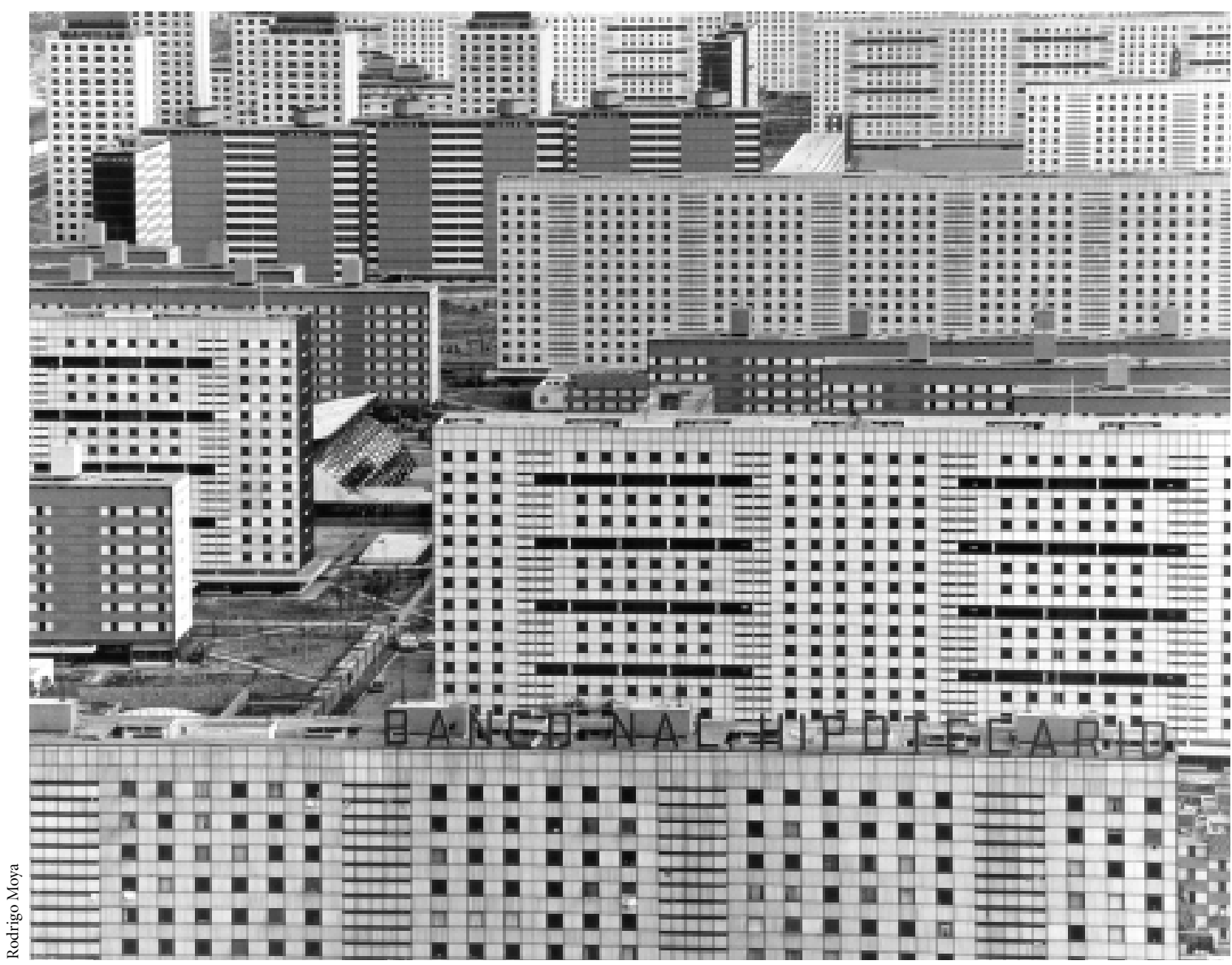

Unidad multifamiliar Tlatelolco, ciudad de México, ca. 1963.

también al tipo de instalaciones, de tal manera que resultan (al menos en parte) redundantes. De esta manera, podemos refrasear su definición homologada para que quede (cambio no incluido en el cuadro 1): "Carencia de recursos para adquirir los satisfactores acostumbrados", haciendo evidente (como en la cita siguiente) que Townsend en realidad no ha abandonado el terreno de las necesidades y sus satisfactores:

Cualquier conceptualización rigurosa de la determinación social de las necesidades desvanece la idea de necesidad absoluta. Y un relativismo total se aplica según la época y el lugar. Los satisfactores básicos (necessities) de la vida no son estáticos. Se adaptan continuamente y se incrementan en la me- dida que hay cambios en la sociedad y en sus productos ${ }^{23}$ (Townsend, 1979b: 17-88, cit. por Sen, 2003: 413).

Aunque no abandona el mundo de las necesidades, se aleja radicalmente de la noción de necesidades humanas universales. Townsend ha sido muy ambiguo en cuanto a amplitud o estrechez de la mirada. Por una parte, ha mantenido una visión del universo de satisfactores y necesidades (aunque no use esos términos sino 'patrones de vida') mucho más amplia que la predominante. También ha sostenido una concepción de los recursos mu-

${ }^{23}$ Aunque me he basado en la traducción de esta fuente, he introducido algunos cambios. 
cho más extensa que la de sólo los ingresos corrientes. En Poverty in the United Kingdom (1979a) usó un conjunto de 60 indicadores de privación que se refieren a aspectos muy variados de la vida, desde alimentación, vestuario, combustible y electricidad, hasta condiciones de trabajo, salud, educación, espacios para el juego de los menores, pasando por condiciones de la vivienda y equipamiento doméstico. Sin embargo, al lado de esta amplitud, ha incurrido en un fuerte reduccionismo al menos en dos ocasiones decisivas. La primera acción reduccionista la llevó a cabo cuando derivó de su afirmación de que los satisfactores básicos de la vida no son estáticos la conclusión de que, para ir actualizando los umbrales a los que llama estándares de suficiencia,

no bastaría con dar cuenta del cambio en los precios, ya que se omitirían las modificaciones en los bienes y servicios consumidos, así como las nuevas obligaciones y expectativas de los miembros de la comunidad. A falta de otro criterio, el mejor supuesto sería vincular la suficiencia con el incremento promedio (o caída) en los ingresos reales (Townsend, 1979b: 17-18, cit. por Sen, 2003: 413).

Esto lo llevó a usar, en su investigación con AbelSmith ${ }^{24}$, como líneas de pobreza 50 y $60 \%$ del ingreso medio de los hogares, que se ha convertido (con pequeñas variantes) en el método oficial de medición de la pobreza de la Organización para la Cooperación y el Desarrollo Económico (OCDE) y de la Unión Europea. Se trata de un relativismo extremo (que termina confundiendo la pobreza con la desigualdad) en el cual, además, se han reducido los recursos a los ingresos corrientes. Con ello los satisfactores se reducen también a aquellos que se pueden adquirir con dinero, en contraste con la amplia gama de indicadores de privación antes mencionada en la que hay algunos rubros (educación, salud, interacción social, alimentos cocinados) que no dependen del ingreso o no solamente de él.

La segunda acción reduccionista que llevó a cabo Townsend en el capítulo 6 de Poverty in the United Kingdom consistió en reducir la amplia gama de recursos (ahí mis-

${ }^{24}$ Abel-Smith y Townsend, 1965. mo concebida) al ingreso. Esto lo hizo cuando, en su búsqueda de la línea de pobreza objetiva ${ }^{25}$, asoció ingresos de los hogares con los puntajes de privación obtenidos por ellos (en un cálculo ilustrativo construido con 12 indicadores de privación directos de los 60 antes mencionados) respecto del estilo de vida dominante:

Al descender en la escala del ingreso, se plantea la hipótesis que en un punto particular para diferentes tipos de familias, un número significativamente grande de ellas reduce su participación en el estilo de vida de la comunidad más que proporcionalmente. Desertan o son excluidos. Estos puntos de ingreso se pueden identificar como la línea de pobreza (Townsend, 1979a: 249).

Con estas acciones reduccionistas que contradicen su amplia visión de recursos, Townsend comparte la visión reduccionista de los medios de casi todos los demás autores.

Sen y Foster, en su segunda definición, reemplazan 'necesidades elementales y esenciales' por capabilities mínimas y habilidades sociales elementales. Nótese la simetría de los adjetivos. Lo necesario, al igual que en la primera definición, resultan ser ingresos ajustados por la diversidad humana (en materia de condiciones, requerimientos y capacidad de transformación de bienes y servicios en $\mathrm{ca}$ pabilities). Así llegamos a la definición homologada: carencia de ingresos ajustados por la diversidad humana para alcanzar capabilities mínimas y habilidades sociales elementales, quedando igual la primera parte de la frase a la de la primera definición. En los ejemplos de los autores se hace referencia, como capabilities mínimas, a evitar el hambre y evitar vivir en la calle, que no son más que un refraseo obvio de las necesidades de alimentación y vivienda. En cuanto a las habilidades sociales elementales, los autores dan los ejemplos de "aparecer en público sin sentirse avergonzado" " "participar en la vida de la comunidad", que pueden verse también como meros refraseos de necesidades humanas como la autoestima y la pertenencia. O bien, si las aceptásemos como capacidades, les serían aplicables las críticas presentadas en la sec-

25 Véase en el cap. 17 (sección 17.1) de Ampliar la mirada el análisis del método de medición propuesto por Townsend al que he llamado "línea de pobreza objetiva". 
ción 5, ya que ambas serían sólo capacidades económicas dependientes de los recursos de la persona. Todos los ejemplos de Sen y Foster se mantienen dentro del concepto de necesidades humanas o, en el mejor de los casos, desarrollan el concepto de capacidades económicas. Sen y Foster no logran deshacerse del concepto de necesidad, pero en el intento lo oscurecen y le quitan la fuerza que lo hace insustituible. Sus dos definiciones son sólo una.

Townsend y Sen, los autores más destacados en la materia, intentan infructuosamente desarrollar enfoques originales y alejarse del concepto de necesidades, por lo cual los he calificado como búsquedas fallidas de un nuevo enfoque de la pobreza. Ambos quedan atrapados en la EPP dominante y han contribuido a configurar, activamente, su rostro actual.

Pasamos ahora al análisis del último subgrupo: el del enfoque economicista dominante. En la definición adoptada en el estudio colectivo editado por Citro y Michael $(1995)^{26}$ se identifica lo necesario sólo como ingreso monetario o cuasi monetario (vales para comida y similares), lo que conlleva un fuerte reduccionismo en la concepción de los recursos. Al definir el para qué, "obtener el consumo de bienes y servicios", hacen explícito el reduccionismo en los satisfactores, al excluir todos los satisfactores que no sean 'objetos' (véase sección 7). A diferencia de otras definiciones, añaden un segundo para al referir el nivel de consumo como el necesario "para alcanzar un nivel de vida mínimamente adecuado”, que sustituye a la satisfacción de las necesidades. Puesto que la única respuesta que podrían dar a cuál es el elemento constitutivo del eje de nivel de vida sería "el consumo de bienes y servicios", que sólo puede medirse a través del gasto incurrido, la definición de pobreza es tautológica, ya que si suponemos que el ahorro, que no está en los propósitos, es igual a cero, ingresos y gasto de consumo son iguales, por lo que la definición rezaría: "carencia de gastos de consumo para alcanzar un nivel de consumo mínimamente adecuado”.

${ }^{26}$ Se trata de un volumen colectivo, resultado de la labor de un grupo de expertos que trabajaron durante dos años y medio, por encargo del Joint Economic Committee del Congreso de Estados Unidos, para hacer "una revisión en profundidad del método de medición oficial de la pobreza del gobierno de dicho país".
Como se señala en la columna de observaciones, los autores están conscientes de la estrechez de su mirada, pero la conciben como una virtud y usan explícitamente los términos pobreza económica y pobreza material: "enfocamos nuestro trabajo en la privación económica, definida de manera estrecha. Nos ocupamos del concepto, definición y medición de la pobreza económica, o lo que muchos llaman pobreza material". Orgullosamente reduccionistas.

Hagenaars (1986) reemplaza necesidad (concepto que paradójicamente no rechaza) por un nivel mínimo de bienestar (utilidad) que, siguiendo a Van Praag, sostiene se puede medir mediante encuestas. El resultado de éstas, al que la autora llama utilidad, es más bien una opinión del entrevistado sobre su propia situación. Hagenaars ignora las críticas al utilitarismo de Sen y Rawls ('gustos baratos' y 'gustos caros'; sección 3, supra). Logra sustituir necesidades por algo que podría llamarse 'cumplimiento de expectativas', cuya pertinencia en el estudio de la pobreza es, sin embargo, muy poco defendible.

Un caso más general entre los utilitaristas es el de Ravallion (1998), quien es el líder intelectual en este tema en el Banco Mundial (BM). Interpretados literalmente, estos economistas postularían que la frase correcta del DRAE es "carencia de lo necesario (gastos de consumo o ingresos) para alcanzar un nivel referencial de utilidad". Sin embargo, hay una simulación de cambio del espacio de ingresos al de utilidad, por medio de la introducción de ajustes en función de las características del hogar (tamaño, estructura de edades, etc.). En vez de referirse descriptivamente a este cambio como lo que es, ingreso ajustado por adulto equivalente $\mathrm{o}$ algo similar, pretenden que se trata de pasar del espacio del ingreso al de la utilidad ${ }^{27}$. Por tanto, interpretada críticamente, la frase quedaría: "carencia de lo

\footnotetext{
${ }^{27}$ Esto se demuestra con una frase de una cita de Deaton y Muellbauer (1991 [1980]), que dice: "Las escalas de equivalencia se basan en el supuesto de que la única diferencia en gustos entre los hogares se debe a las características observables". O dicho de otro modo, las funciones de utilidad son idénticas para todas las personas/hogares por adulto equivalente. Pero, como se mostró en la sección 4 supra, para sostener el carácter imperativo de calcular las unidades equivalentes, los autores tienen que recurrir al concepto de necesidad, mostrando que éste, rechazado por la puerta delantera, vuelve a entrar por la puerta trasera en la teoría neoclásica del consumidor.
} 


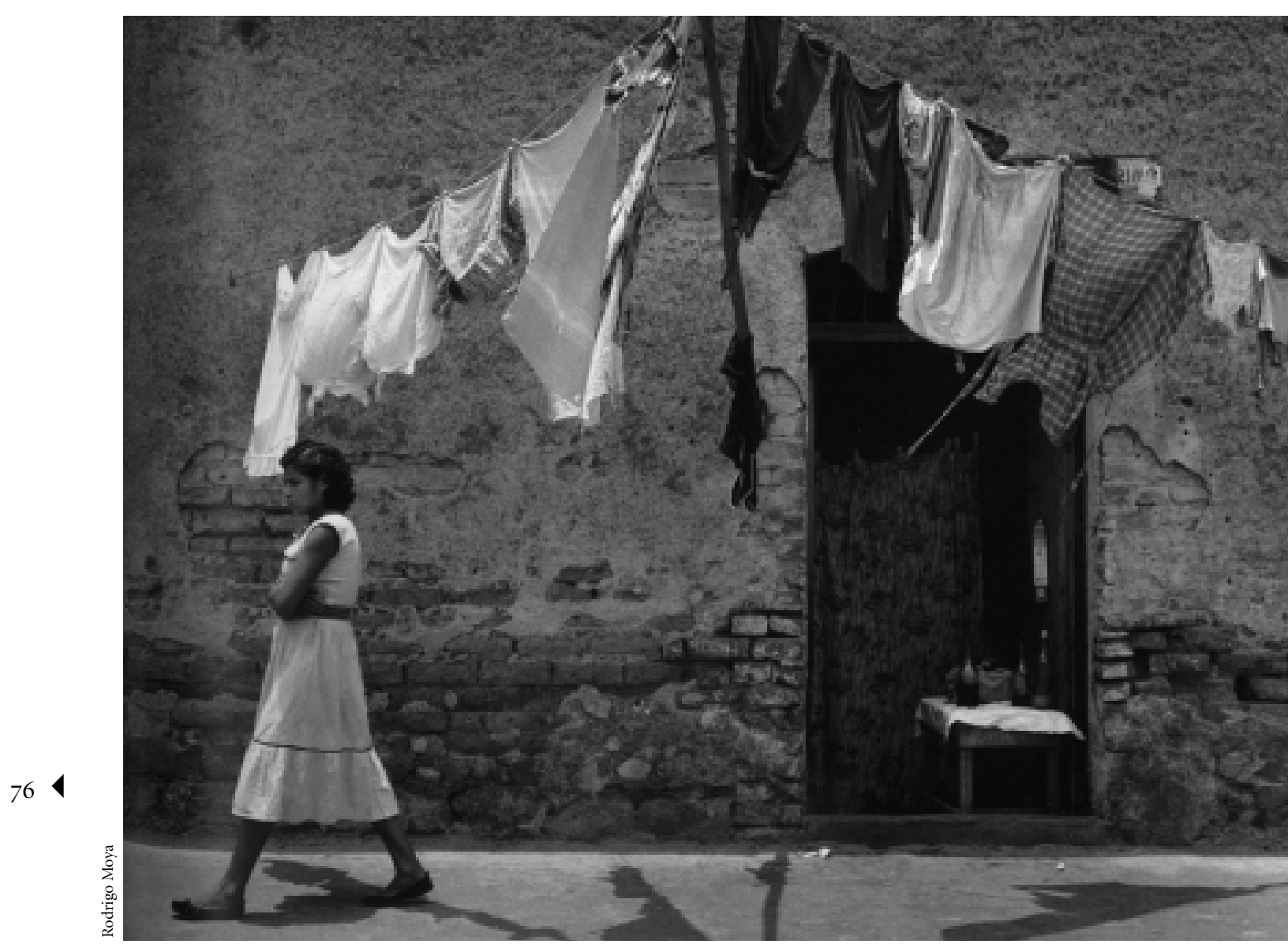

Tacuba, ciudad de México, ca. 1960.

necesario (gastos de consumo o ingresos) para alcanzar un nivel referencial de gastos de consumo o ingresos por adulto equivalente", o de manera más descarnada, "carencia de los ingresos necesarios para alcanzar un nivel referencial de ingresos". Como se muestra en el cuadro 1 (columna observaciones), Ravaillon admite que la teoría no ayuda a la definición del nivel referencial de utilidad por lo cual se necesitan juicios normativos externos para fijar la línea de la pobreza. La determinación de ese nivel referencial de ingresos es totalmente arbitraria en la práctica del BM y en la de esta clase de economistas, lo que muestra el tipo de ciencia que practican.

De lo que llevamos analizado queda claro que los intentos de Sen y Townsend por abandonar el concepto de necesidad como elemento constitutivo del propósito en el enunciado del concepto de pobreza son fallidos. También que los 'utilitaristas' resultan no serlo, puesto que su concepto es imposible de medir, y que terminan sustituyéndolo o por "satisfacción de expectativas" o por la tautología "ingresos insuficientes para alcanzar un nivel de ingresos referencial”, definiciones en las que los ingresos son propósito y medio. Tenemos que concluir que el carácter indispensable del concepto de necesidades se termina imponiendo.

Contrasto ahora las definiciones de los conceptos de pobreza económica (del ser: PES; y del estar: PEE) desarrolladas en Ampliar la mirada (renglones 4 y 5, cuadro 1) con todas las anteriores. Si bien el concepto de PEE parece 
cercano al que he llamado enfoque convencional de necesidades de la pobreza, representado por la definición de Altimir, la primera de Sen y Foster y la de Boltvinik (MMIP), hay dos diferencias de entrada: 1) la pobreza económica del estar incluye aplicación de capacidades efectivas; 2) se refiere a la satisfacción de las necesidades efectivamente desarrolladas ${ }^{28}$. Sólo algunas personas han desarrollado extensionalmente sus necesidades de manera que cubran, por ejemplo, toda la gama planteada por Maslow; en muchas personas están ausentes las necesidades de autorrealización y las cognitivas superiores. Por ello y por otras razones, las dos dimensiones de la pobreza económica (PES y PEE) deben siempre evaluarse de manera simultánea y vinculándolas con las dos categorías de pobreza humana.

Juan, el antropólogo físico que he usado como ejemplo en Ampliar la mirada, ha de ser situado, ante todo, en las escalas de pobreza/riqueza humana del ser y del estar. Supongamos que Juan (quien es rico humanamente - necesita mucho y tiene ampliamente desarrolladas sus capacidades- y se mantendrá muchos años en esa situación, aunque esa riqueza pueda irse deteriorando si no se continúa desarrollando) no puede trabajar como antropólogo físico y, en consecuencia, se sitúa en pobreza humana del estar porque no puede satisfacer su necesidad de autorrealización ni aplicar (y, por tanto, ni seguir desarrollando) sus capacidades centrales. Cabe aquí hacer notar que esta situación sería el resultado de una pobreza económica tanto del ser como del estar: no habría tenido la oportunidad de trabajar como antropólogo físico. Son estas pobrezas económicas las que generan su ubicación en la pobreza humana del estar. Podría no ser una carencia económica, sino afectiva, la que lo hace estar humanamente pobre: una separación amorosa que dejara esta necesidad insatisfecha. Si Juan fuese todavía joven y

${ }^{28}$ Evaluar la situación de las personas que ni siquiera han desarrollado las cuatro necesidades básicas de la motivación deficitaria con base en sus necesidades efectivas parecería ir contra principios éticos básicos y podría conducir a resultados perversos: los más pobres podrían resultar mejor situados que otros menos pobres. Sin embargo, hay que tomar en cuenta que, como se argumenta enseguida, la PEE no debe evaluarse de manera independiente de la PES, donde no hay recorte de necesidades (ni de capacidades): todos son evaluados contra el espectro completo de necesidades humanas. el evento bajo consideración (no consigue trabajo de antropólogo físico) reciente, su necesidad de entendimiento acerca del origen del hombre y su vocación de autorrealización como antropólogo físico seguirían vivas. Si Juan no se hubiese declarado derrotado sentiría la necesidad de explorar otras vías para su autorrealización, tanto en la antropología física (v.g. dar clases) como en la música (la otra vocación de Juan) o en ambas. Al evaluar la situación de Juan, en cualquier momento de su vida en las cuatro dimensiones (lo que debe concebirse como su ubicación en uno de los cuatro cuadrantes de dos ejes de coordenadas: uno para la dimensión humana, otro para la económica), podemos captar los retos del florecimiento humano y de la superación de la pobreza, y sus interrelaciones, como proceso. A diferencia del enfoque tradicional en el estudio de la pobreza, tenemos aquí, incluso limitándonos a la evaluación de la pobreza económica, un espacio bidimensional.

Se pueden identificar las siguientes diferencias entre el nuevo enfoque de la pobreza económica y el convencional de necesidades: 1) No hay en el nuevo enfoque acotamiento o reducción de necesidades. 2) La visión dinámica (desarrollo) de las necesidades se contrapone al concepto estático de satisfacción de necesidades fijas. 3) La incorporación del desarrollo y aplicación de capacidades rescata el lado activo del ser humano y refuerza la visión dinámica del florecimiento humano a través de la unidad dialéctica necesidades-capacidades, con toda la riqueza analítica que conlleva. 4) La sustitución de recursos acotados por fuentes de bienestar y oportunidades (de trabajo, estudio, etc.) amplía la visión de los aspectos económicos relacionados con el florecimiento humano, de tal manera que, por ejemplo, se supera la visión del trabajo como mero medio de obtención de ingresos y se incorpora su papel central en la aplicación (y desarrollo ulterior) de capacidades. 5) El paso de una evaluación unidimensional a una bidimensional (pobreza económica del ser y del estar) permite captar aspectos dinámicos que el enfoque estático no puede percibir. 6) El vínculo entre pobreza económica y pobreza humana transforma radicalmente los referentes del concepto y las evaluaciones se vuelven mucho más dinámicas como lo muestra el párrafo precedente. 


\section{LA ESTRECHA MIRADA DE LA ECONOMÍA POLÍTICA DE LA POBREZA (EPP)}

\section{I. Las necesidades y los satisfactores}

Es preciso hacer la distinción entre necesitar o necesidades, por un lado; y desear o apetecer, o deseos y apetencias, por el otro. Para ello conviene retomar a David Wiggins (2002 [1987]), quien dice que una persona necesita X [absolutamente,] si y sólo si ella resultará dañada si carece de $X$. Es el daño resultante lo que distingue lo necesitado de los deseado o apetecido. Nótese que ésta es una definición, formal y muy precisa, de lo necesitado (del satisfactor) y no de la necesidad. Ésta la define el propio Wiggins "como estados de dependencia (con respecto a no ser dañado), que tienen como sus objetos apropiados las cosas necesitadas (o, más estrictamente, tener o usar cosas)"29. Añade Wiggins que a diferencia de desear, "necesitar no es evidentemente un verbo intencional": "Lo que necesito no depende del pensamiento o de cómo funciona mi mente (o no sólo de ello), sino del mundo como éste es" (Wiggins, 2002 [1978]).

Para emprender la crítica externa de la EPP y la formulación de un nuevo enfoque es necesario partir de conceptos precisos, como el de necesidad, y del ser humano tal como éste es: ser natural activo, social y consciente, que se distingue de las demás especies del reino animal. El ser humano, como todo ser vivo, requiere objetos externos para reproducir su propia vida, lo que, dice Marx, lo convierte en un "ser dependiente y sufriente". El ser humano necesita, pues, objetos externos (bienes). Pero el ser humano es también un ser activo que (como especie) sólo puede satisfacer sus necesidades a través de su actividad vital, el trabajo, que se dirige de manera mediada a la satisfacción de necesidades. Puesto que sin el trabajo el ser humano no es tal, éste se transforma en necesidad central. El ser humano necesita su propia actividad. El ser

\footnotetext{
${ }^{29}$ Mientras en la primera parte no parece haber ningún reduccionismo, ya que $\mathrm{X}$ puede ser un objeto, una relación o la realización de actividades, en la segunda sí hay reduccionismo, ya que si hablamos de tener o usar cosas se excluye la necesidad de relaciones con otras personas o la necesidad de realizar ciertas actividades.
}

humano necesita también actividades de otras personas que le benefician (servicios). Pero el ser humano es también un ser social. Para Marx, el 'hombre' no puede llevar una vida humana, no puede ser hombre como tal más que en su relación con los demás y a consecuencia de esa relación. Por tanto, el ser humano necesita relacionarse con otros seres humanos. Necesita relaciones. Por último, el ser humano es también un ser consciente, lo que entre otras cosas quiere decir que su propia vida le es objeto. La actividad vital consciente diferencia al hombre de la actividad vital animal, dice $\operatorname{Mar}^{30}$. Por tanto, el ser humano necesita saber y entender, es decir, necesita información, conocimientos, ideas, marcos conceptuales, teorías o explicaciones.

De la reflexión anterior podemos derivar una tipología de satisfactores de las necesidades humanas: 1) objetos externos (bienes); 2) actividades de otras personas que nos proporcionan beneficios (servicios); 3 ) actividades del sujeto; 4) relaciones (asociadas a las cuales se llevan a cabo actividades compartidas con quienes se establecen las relaciones); 5) información, conocimientos, teorías. A partir de la amplia gama de satisfactores que manejan Max Neef et al. en su "Matriz de necesidades y satisfactores"31 (reproducida en el capítulo 5 de Ampliar la mirada) y previo tamiz crítico, podemos concluir que es necesario añadir capacidades e instituciones a la tipología anterior, por lo cual la tipología completa de satisfactores queda integrada como sigue: 1) objetos o bienes; 2) servicios; 3) relaciones; 4) actividades; 5) conocimientos y teorías; 6) capacidades, y 7) instituciones.

En Ampliar la mirada analizo comparativamente las teorías de las necesidades humanas de Marx (directamente y a través de la visión de György Márkus, Agnes Heller y J. P. Terrail), de Maslow, Fromm, Maccoby, Max Neef et al., Doyal y Gough y Nussbaum. Una conclusión de dicho análisis es que se puede sostener con argumentos racionales que, si pudiésemos interactuar con estos autores en un proceso que llevase a eliminar sus diferen-

\footnotetext{
${ }^{30}$ Véase el cap. 2 de Ampliar la mirada, en la cual se desarrollan estas ideas siguiendo la lectura magistral de la visión antropológica de Marx que ha hecho György Márkus, 1985.

31 Página 42 de Desarrollo a escala humana. Una opción para el
} futuro, Max Neef et al., 1986. 
cias puramente taxonómicas, si bien no habría consenso en cuanto a la teoría de la jerarquía de necesidades de Maslow (1943 y 1987 [1954]), sí habría consenso sobre su lista de necesidades, salvo las estéticas ${ }^{32}$. Por tanto, en lo que sigue me apoyaré en el esquema de Maslow con la omisión de las necesidades estéticas. Su esquema completo de necesidades consiste (véase el capítulo 3 de Ampliar la mirada) en: 1) las libertades sociales como prerrequisito para la satisfacción de todas las necesidades; 2) una jerarquía de necesidades formada por cinco niveles, de más prepotentes a menos: fisiológicas, de seguridad, afectivas (amor, afecto, pertenencia), de estima (que divide en dos: los logros que forman la base de la autoestima y la reputación) y de autorrealización; 3) las necesidades cognitivas, con su propia jerarquía (saber y entender), y 4) las necesidades estéticas.

Agrupando de manera un poco diferente las necesidades enumeradas por Maslow y adoptando la tipología de siete tipos de satisfactores derivada antes, he definido los contenidos de las dos primeras columnas del cuadro 2 (p. 81). En las celdas de la primera columna se presentan cuatro grupos de necesidades, en el siguiente orden: 1) De sobrevivencia (o materiales), que podemos asociar de manera aproximada con los dos primeros niveles del esquema de Maslow: necesidades fisiológicas y de seguridad. Los ejemplos presentados en el cuadro son alimentación, refugio y seguridad. 2) Cognitivas (saber y entender). 3) Emocionales, en que quedan ubicadas claramente la necesidad de amor, afecto y pertenencia de Maslow, el tercer nivel de su jerarquía, y la parte de reputación de la necesidad de estima, cuarto nivel de su jerarquía. 4) Necesidades de crecimiento, entre las que he incluido la otra parte de las necesidades de estima, a la que Maslow llama las $b a-$ ses de la autoestima (formadas por los logros de la persona), así como la necesidad de autorrealización. En las celdas de la columna 2, y a partir de la tipología de satisfactores desarrollada, se presentan algunos satisfactores identificados para cada grupo de necesidades, clasificados en principales y secundarios según el papel que de-

${ }^{32} \mathrm{El}$ análisis de cada esquema se lleva a cabo en los caps. 2, 3, 4, 5, 6 y 8 , mientras el comparativo se presenta en el cap. 11 . sempeñan en la satisfacción de la necesidad. Para evitar un cuadro muy complejo he evitado ser exhaustivo.

\subsection{Fuentes de bienestar o recursos}

Para la tercera columna del cuadro 2 podemos utilizar tanto la concepción usual de recursos como la de fuentes de bienestar. Con base en esta última noción, que he venido utilizando desde hace muchos años ${ }^{33}$, he sostenido que el bienestar de los individuos y de los hogares depende de las siguientes fuentes directas: 1) el ingreso corriente; 2) el patrimonio básico, entendido como el conjunto de bienes y activos durables que proporcionan servicios básicos a los hogares; 3) los activos no básicos y la capacidad de endeudamiento del hogar; 4) el acceso a los bienes y servicios gratuitos que ofrece el gobierno; 5) el tiempo disponible para el descanso, el trabajo doméstico, la educación y el tiempo libre; y 6) las habilidades y conocimientos de las personas, fundamentales en el desempeño de cualquier actividad, una parte de los cuales incide en el desempeño de las actividades, mientras otra debe verse como satisfactor directo de las necesidades cognitivas del ser humano. Ni el tiempo ni las habilidades y los conocimientos son concebidos como medios de cambio para la obtención de ingresos, sino como satisfactores directos de necesidades ${ }^{34}$.

\footnotetext{
33 Originalmente lo formulé en Julio Boltvinik, 1990.

${ }^{34}$ Concebir las capacidades (y conocimientos) al mismo tiempo como fuente de bienestar y satisfactor parece una inconsistencia en la taxonomía adoptada, pero creo que no lo es. La relación entre fuentes de bienestar y satisfactores no es siempre la de la mediación de las primeras para el acceso a los segundos, como ocurre con los ingresos corrientes que permiten adquirir satisfactores directos de la necesidad. Pero los activos básicos específicos como vivienda, mobiliario y equipos domésticos son bienes que no han de pasar por la mediación de un intercambio para transformarse en satisfactores; por lo que han de pasar, en cambio, es por el uso: una casa deshabitada, un refrigerador vacío o apagado, un equipo de sonido que no se usa, son fuentes de bienestar pero no son satisfactores (aunque podrían serlo si se habitaran, se abastecieran con alimentos, se prendieran). Pero ser satisfactores no les resta la característica de fuente de bienestar. El acceso a los servicios gubernamentales (que podría haberse formulado como derecho de acceso o titularidad) es similar al ingreso corriente y al tiempo disponible: sólo si se "canjean" por satisfactores específicos como educación pública, bienes adquiridos, tiempo dedicado a un fin específico, se transforman en satisfactor. Son satisfactores las capacidades efectivamente
} 
Las tres primeras fuentes de bienestar representan recursos económicos privados (flujos o acervos); la cuarta categoría representa el flujo de recursos económicos públicos (el así llamado salario social). En conjunto, estas cuatro categorías representan los recursos económicos monetizables (que se pueden expresar en dinero, no transformar en él). La quinta y sexta categorías tienen sus propias unidades de medida y no se pueden reducir a valores monetarios. En suma, los recursos económicos monetizables, el tiempo libre y los conocimientos y habilidades son las tres dimensiones irreductibles de las fuentes de bienestar. Estas fuentes pueden evolucionar de maneras diversas, incluso contrapuestas, debido a que están sujetas a distintos factores determinantes ${ }^{35}$.

Algunos economistas ortodoxos han desarrollado un enfoque cercano al de fuentes de bienestar que reconoce la insuficiencia del ingreso corriente como un indicador de la disposición de recursos y busca superarlo a través de "indicadores compuestos del estatus económico de los hogares". Aldi Hagenaars (1986: 9-10) describe las adiciones sucesivas de rubros a estos indicadores compuestos. Poniéndolos juntos, la disposición sobre recursos sería igual a la suma del ingreso corriente más el valor de la producción doméstica, el valor del ocio, el flujo anual derivado de los acervos netos de capital y el valor de las transferencias no monetarias (públicas y privadas). Aunque el punto de partida de estos enfoques y el mío son similares (la visión integral del funcionamiento del hogar), destacan cuatro diferencias generales: 1) todos los elementos constitutivos son vistos estrictamente como medios en el enfoque del estatus económico, mientras que yo concibo al tiempo, y a los conocimientos y habilidades como, al menos en parte, fines en sí mismos; 2) mi postura sobre el carácter irreductible del tiempo y los conocimientos con-

utilizadas para la satisfacción y son fuentes de bienestar las capacidades efectivas disponibles. En el fondo es la misma distinción de acervos y uso corriente. Las fuentes de bienestar son satisfactores potenciales o pueden transformarse en satisfactores efectivos.

${ }^{35}$ Más allá de la posibilidad lógica, así ha ocurrido en México y en otros países de América Latina en décadas recientes. Para un análisis de la evolución radicalmente distinta de las fuentes de bienestar en México y, por tanto, de la incidencia de la privación humana en diferentes componentes, véase Julio Boltvinik, 2003. Un resumen de este trabajo se incluye en el cap. 19 de Ampliar la mirada. trasta con la reducción a términos monetarios de todos los elementos en el enfoque del estatus económico; 3 ) la ausencia en mi enfoque de condiciones de maximización que están presentes en algunos de estos enfoques; 4) mi enfoque lo aplico cotidianamente en la medición de la pobreza, mientras que el del estatus económico se ha aplicado sólo excepcionalmente.

\subsection{El mapa conceptual de la EPP}

En la columna 3 del cuadro 2 se presentan las fuentes de bienestar (o recursos), clasificadas en dominantes (o principales) y secundarias, que se asocian, en cada renglón, con las necesidades y satisfactores que se han incluido en las dos primeras columnas. El cuadro queda así completo: en las columnas: necesidades, satisfactores y recursos; en los renglones: los cuatro grupos de necesidades identificadas de modo que, en cada celda de las columnas 2 y 3 , se identifican los satisfactores y los recursos asociados con cada grupo de necesidades, particularmente con sus ejemplos. Tanto los satisfactores como los recursos han sido clasificados en principales y secundarios. Cada enfoque de la pobreza puede ser caracterizado según la amplitud o estrechez con la cual concibe las necesidades humanas, los satisfactores que posibilitan su satisfacción y los recursos (o fuentes de bienestar) que hacen posible el acceso a los satisfactores.

En el cuadro 2 he sombreado los elementos que suelen identificar quienes, en la sección anterior, clasifiqué como autores de enfoques convencionales de necesidades y de búsquedas fallidas de un nuevo enfoque (Altimir, Sen y Foster en sus dos definiciones, y Townsend ${ }^{36}$ : sólo una parte de los elementos del primer y del segundo renglón. Las definiciones tautológicas de Citro y Michael y de Ravallion ni siquiera se pueden analizar plenamente en el

\footnotetext{
36 Aunque Boltvinik-MMIP fue incluido, en la sección anterior, como enfoque convencional de las necesidades, y lo es en la medida que parte de las necesidades estáticas, iguales para todos y escindidas de las capacidades, no incurre en el reduccionismo señalado en el texto en buena medida porque, al reconocer como recursos al tiempo y a las capacidades, identifica en el eje del nivel de vida las necesidades emocionales y de crecimiento, cubriendo así los cuatro renglones del cuadro.
} 
Cuadro 2. Satisfactores y recursos (principales y secundarios) asociados con cuatro tipos de necesidades (materiales, cognitivas, emocionales, de desarrollo)

\begin{tabular}{|c|c|c|}
\hline $\begin{array}{l}\text { Tipos de necesidades } \\
\text { (ejemplos de) }\end{array}$ & $\begin{array}{c}\text { Tipo de satisfactores } \\
\text { principales/secundarios }\end{array}$ & $\begin{array}{l}\text { Recursos (fuentes de bienestar) } \\
\text { principales/secundarios }\end{array}$ \\
\hline $\begin{array}{l}\text { Sobrevivencia o materiales } \\
\text { (alimentación, refugio, seguridad) }\end{array}$ & $\begin{array}{l}\text { Objetos (alimentos, vivienda), } \\
\text { Instituciones (familia, seguros)/ } \\
\text { actividades familiares (cocinar, limpiar) }\end{array}$ & $\begin{array}{l}\text { recursos monetizables }{ }^{\star} / \\
\text { tiempo; conocimientos } y \text { habilidades }\end{array}$ \\
\hline $\begin{array}{l}\text { Necesidades cognitivas } \\
\text { (saber, entender, educarse) }\end{array}$ & $\begin{array}{l}\text { Actividades del sujeto } \\
\text { (leer, estudiar, investigar) } \\
\text { Conocimientos, teorías } \\
\text { objetos (educación, libros) }\end{array}$ & $\begin{array}{l}\text { Tiempo, conocimientos y habilidades } \\
\text { recursos monetizables }\end{array}$ \\
\hline $\begin{array}{l}\text { Emocionales y de estima } \\
\text { (afecto, amistad, amor; reputación) }\end{array}$ & $\begin{array}{l}\text { Relaciones primarias y secundarias/ } \\
\text { actividades con pareja o amistad; } \\
\text { capacidades, } \underline{\text { objetos }}\end{array}$ & $\begin{array}{l}\text { Tiempo, conocimientos y habilidades/ } \\
\underline{\text { recursos monetizables }}^{\star}\end{array}$ \\
\hline $\begin{array}{l}\text { De crecimiento } \\
\text { (bases de autoestima: logros, } \\
\text { autorrealización) }\end{array}$ & $\begin{array}{l}\text { Capacidades y actividades del sujeto/ } \\
\text { (cumplir roles; realizar potencial) } \\
\text { Trabajo, relaciones secundarias, objetos }\end{array}$ & $\begin{array}{l}\text { Conocimientos y habilidades, tiempo/ } \\
\underline{\text { recursos monetizables }}^{\star}\end{array}$ \\
\hline
\end{tabular}

* Incluye ingreso corriente; activos básicos; activos no básicos; acceso a bienes y servicios gratuitos.

cuadro. Para hacerlo, hay que eliminar la primera columna o sustituirla por utilidad (cumplimiento de expectativas en el caso de Hagenaars). Una parte de los enfoques dominantes en la EPP reconoce sólo necesidades 'materiales' como la alimentación, la vivienda, y otras cuya satisfacción depende principalmente del acceso a recursos monetizables. Algunos tienen una postura ambigua respecto a las necesidades cognitivas, que reconocen a veces como necesidad educativa. En general, perciben la educación más como medio para 'acumular el capital humano' (y, por tanto, los ingresos esperados en el mercado de trabajo) que como forma de satisfacción de las necesidades cognitivas del ser humano. Como se aprecia en los capítulos 15 a 19 de Ampliar la mirada, salvo excepciones, en la medición de la pobreza no se suelen incluir las necesidades cognitivas. En las variantes de presupuestos familiares del método de línea de pobreza, suele haber una identificación de algunos satisfactores requeridos para la educación, mostrando así el reconocimiento implícito de al menos una parte de la necesidad educativa. Para distinguir la identificación plena de las necesidades de sobrevivencia o materiales y el reconocimiento esporádico, y ambiguo, de las necesidades cognitivas, en esta parte de los enfoques convencio- nales he sombreado estas últimas necesidades con un tono más oscuro.

Estos enfoques convencionales reconocen sólo los objetos (bienes y servicios) como satisfactores, y como único recurso los monetizables (aún peor: la mayor parte de las veces, dentro de éstos, sólo reconocen el ingreso corriente). Por tanto, incluso dentro de los renglones 1 y 2 suelen desconocer que se requieren actividades (cocinar, abastecer, leer, estudiar) y no sólo objetos (bienes y servicios) para satisfacer necesidades como la alimentación y las cognitivas y, por tanto, que se requiere de los recursos tiempo y habilidades. Como no identifican los renglones 3 y 4 , fuera de una parte de los renglones 1 y 2 lo omiten todo ${ }^{37}$.

37 Un ejemplo es el del conjunto de recomendaciones del panel sobre pobreza y asistencia familiar del National Research Council de Estados Unidos antes mencionado, y cuyas conclusiones han sido publicadas en la obra editada por Citro y Michael arriba citada. Los autores dicen: "Definimos pobreza como privación económica. Una manera de expresar este concepto es que se refiere a la carencia de recursos económicos (ingreso monetario o cuasi monetario) para consumo de bienes y servicios económicos (como alimentos, vivienda, vestuario, transporte)" (1995: 19). Sólo reconocen algunas necesidades que corresponden al estereotipo de las necesidades materiales, lo que deja el enfoque reducido al primer renglón (la educación y, con ella, las necesidades cognitivas completas quedan fuera). Los únicos satisfactores reconocidos son, explíci- 
El enfoque economicista dominante (Citro y Michael, Ravallion y Hagenaars, entre los autores del cuadro 1, pp. 70-71), el más ortodoxo en la EPP, desconoce las necesidades humanas y concibe la pobreza no como insatisfacción de necesidades sino como un nivel de vida por debajo del mínimamente adecuado, o un nivel de utilidad por debajo del 'referencial'. En este caso tendríamos que cambiar el contenido de la columna 1 , de necesidades a utilidad o nivel de vida (lo que haría desaparecer los renglones, ya que utilidad y nivel de vida son elementos homogéneos, de los cuales, como el valor de cambio, sólo importa su cantidad), y rebautizar la columna 2 de 'satisfactores' a 'proveedores de nivel de vida o utilidad'.

La economía política de la pobreza es reduccionista en un triple sentido: 1) Los enfoques convencionales de necesidades reducen éstas a las 'materiales' (aunque a veces incluyen la educación) y suelen desconocer las necesidades de seguridad y sus principales satisfactores (instituciones como la familia, los seguros y el Estado. El enfoque economicista dominante desconoce las necesidades y las sustituye por utilidad. En ambos casos, el cuadro 2 se coneducativa) en un cuadro de un renglón único. 2) Todos los enfoques dominantes en la EPP (incluido el grupo de búsquedas fallidas de un nuevo enfoque) reducen los satisfactores (o 'proveedores de utilidad') a los objetos (bienes y servicios), desconociendo los demás tipos de satisfactores (relaciones, actividades, conocimientos y teorías, capacidades, instituciones). 3) Todos los enfoques dominantes en la EPP reducen los recursos a los monetizables y, con mucha frecuencia, sólo al ingreso corriente. Tiempo, y conocimientos y habilidades, son las fuentes de bienestar (recursos) constantemente ignoradas en estos enfoques convencionales. Además, quienes sólo tomen en cuenta el ingreso corriente también ignoran los otros tres recursos que he llamdo monetizables: el acceso a bienes y servicios gratuitos, y los activos disponibles, tanto básicos como no básicos.

tamente, los bienes y servicios, y sólo se reconocen los ingresos (ni siquiera el conjunto de lo que en el cuadro 2 se llaman los recursos monetizables) como recursos. Se pueden añadir muchos otros ejemplos, tanto de académicos como de organismos internacionales que confirman que éste es el enfoque dominante.

En el caso del enfoque convencional de necesidades, las columnas son las mismas del cuadro 1. En el enfoque economicista dominante las columnas se transforman en utilidad o nivel de vida, proveedores de utilidad o de nivel de vida, e ingresos (el cuadro tendría un renglón único).

Los enfoques sominantes en la EPP tampoco se pueden percatar de que algunas necesidades "inmateriales" requieren también objetos (bienes y servicios) como satisfactores, y recursos económicos monetizables, como se apunta en el cuadro (palabras en cursivas y subrayadas), por lo que incluso calculan mal sus líneas de pobreza, ya que no identifican una parte de los requerimientos monetarios. Algunos ejemplos de objetos omitidos son los bienes y servicios que se asocian a las relaciones (necesidades emocionales). En las actividades con la pareja surgen necesidades de bienes y servicios (restaurantes, espectáculos, hoteles, anticonceptivos, etc.). En las actividades del sujeto, los bienes y servicios que se ocupan en ellas (pinturas y lienzos, el pintor; libros, computadoras, Internet, el escritor y el investigador científico, aunque se ha generalizado de manera creciente la necesidad de una computadora y del acceso a Internet).

Para algunas necesidades como la alimentación y el refugio (renglón 1), los satisfactores principales son bienes (los alimentos y la vivienda); para otras, como la atención a la salud, son bienes y servicios (la atención médica y los medicamentos); en las necesidades de seguridad, que he agrupado como parte de las materiales, y que suelen ser ignoradas por la EPP, el satisfactor principal es una institución: la comunidad o el Estado, la familia o los seguros; en las necesidades cognitivas (renglón 2) las actividades del sujeto, por una parte, y los conocimientos y teorías, por la otra, representan los satisfactores principales $^{38}$, aunque el servicio educativo y bienes como libros y computadoras son importantes satisfactores secundarios; para las necesidades emocionales, en cam-

\footnotetext{
${ }^{38}$ La sabiduría convencional establece que son los servicios pedagógicos proporcionados en la escuela el principal satisfactor de las necesidades de saber y de entender. Creo que esta afirmación puede ser válida para el desarrollo de algunas habilidades como leer y escribir. Sin embargo, lo dicho en el texto me parece la verdad en la mayor parte de los casos, sobre todo cuando se trata de entender.
} 


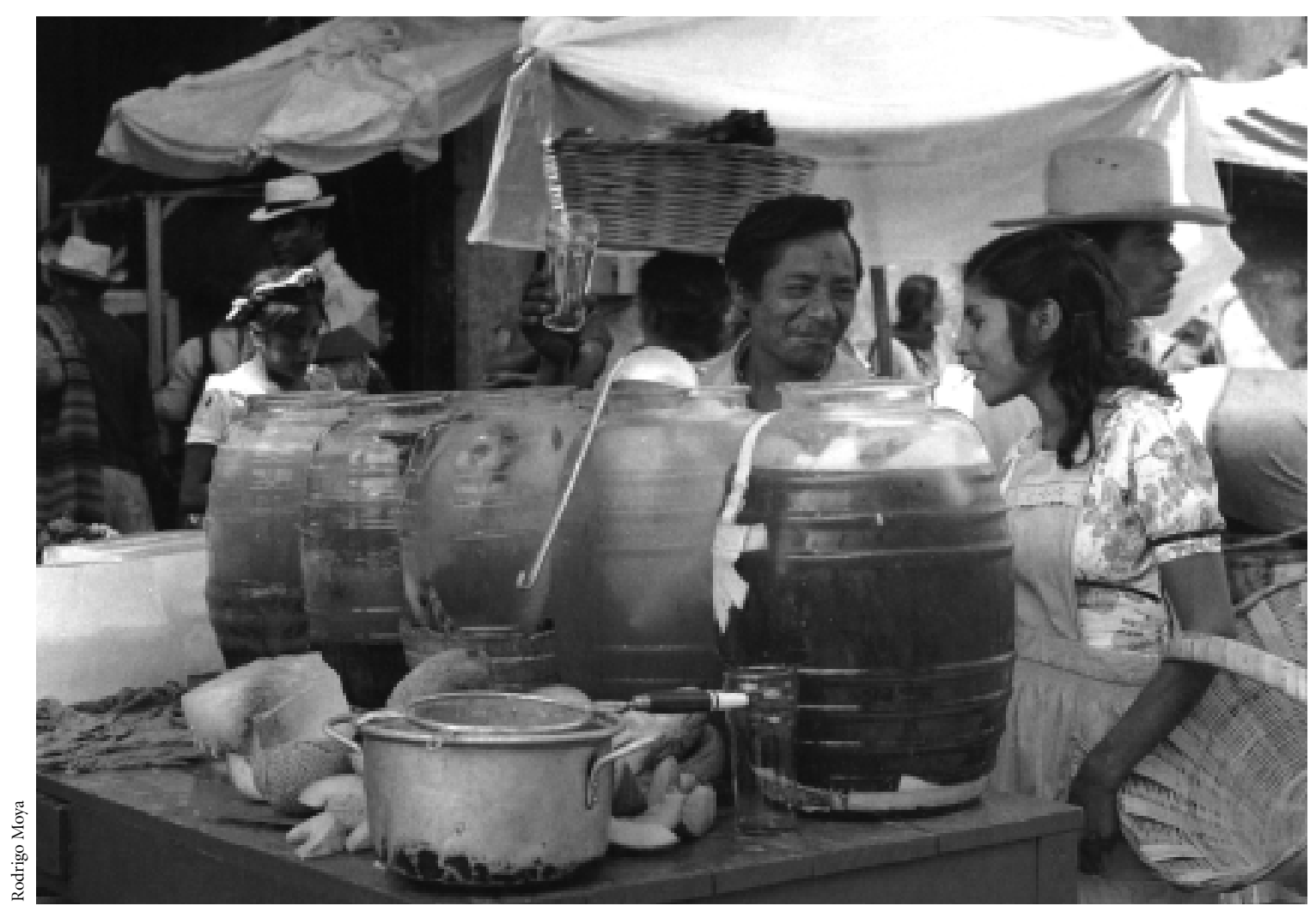

Mercado de Oaxaca, Oaxaca, 1963.

bio, los satisfactores centrales son las relaciones primarias, y para las de estima son las relaciones secundarias (renglón 3); para las necesidades de crecimiento (logros que forman las bases de la autoestima, y autorrealización, renglón 4), la satisfacción se deriva sobre todo de las capacidades y actividades del sujeto, que constituyen los satisfactores principales. Sin embargo, en casi todos los casos, aparte del satisfactor principal intervienen satisfactores secundarios o complementarios: actividades familiares en las necesidades de sobrevivencia, actividades con otras personas en las necesidades emocionales y de estima; objetos tanto en éstas como en las necesidades de crecimiento.

En cuanto a los recursos, en el cuadro se muestra que, cuando el satisfactor dominante es un objeto (bien o servicio), los recursos principales son los que he llamado monetizables (ingreso corriente, activos básicos, activos no básicos, acceso a bienes y servicios gratuitos). En cambio, cuando los satisfactores principales son relaciones o actividades del sujeto, los recursos principales son el tiempo (que se dedica a cultivar la relación o a realizar la actividad) y los conocimientos y habilidades, o capacidades (que se ponen en juego en ambos casos). En todos los casos se requiere que el individuo invierta tiempo personal. En algunos casos este tiempo es un recurso secundario, como el tiempo que dedicamos a comer o a ir al médico (aunque no lo es el dedicado al abasto de alimentos y a su preparación), pero cobra mucha mayor centralidad el requerido para cultivar las relaciones y es totalmente determinante el empleado para realizar las actividades propias del sujeto que sustentan la autoestima, la autorrealización y el desarrollo cognitivo.

De lo dicho se desprende que el triple reduccionismo de aquellos enfoques convencionales que reconocen las ne- 
cesidades o conceptos que se pueden reformular en estos términos está estructuralmente vinculado: 1) omiten las necesidades emocionales y de crecimiento ( $\mathrm{y}$ con frecuencia las cognitivas), y en el segundo grupo las sustituyen con la utilidad;2) omiten los satisfactores 'relaciones' y 'actividades', asociados con las necesidades omitidas; y por último, 3) omiten los recursos 'tiempo' y 'conocimientos/habilidades', asociados con los satisfactores omitidos.

El cuadro 2 parece estar situado en el eje del florecimiento humano (EFH). Esta percepción se deriva de la inclusión en él de necesidades 'no materiales' (cognitivas, emocionales y de crecimiento) y, en consecuencia, de la inclusión de satisfactores como las relaciones. Las dos primeras columnas son perfectamente consistentes con el EFH o con el eje del nivel de vida (ENV). Pero la inclusión después de estas dos columnas de una tercera (y última) referida a recursos (fuentes de bienestar), deja en claro que la perspectiva que interesa en el cuadro es sólo la económica, lo que sitúa al cuadro en el ENV. Un cuadro similar situado en el EFH tendría que tener una o cada necesidad desde la perspectiva biológica, psicológica o filosófica. Si a un cuadro así le aplicásemos la operación del recorte (de las perspectivas no económicas) por la cual, según se ha explicado, se pasa del eje de florecimiento humano (EFH) al eje del nivel de vida (ENV), sólo eliminaríamos la(s) columna(s) de la(s) perspectiva(s) biológica, psicológica o filosófica, y todo lo demás quedaría igual: llegaríamos al cuadro 2. El cambio, por tanto, sería nada más de perspectiva, ya que ahora las relaciones de la persona y sus actividades, por ejemplo, interesarían sólo en cuanto generan requerimientos de recursos, pero no en sus contenidos sustantivos, como sí ocurre cuando nos situamos en el EFH.

El cuadro 2 dibuja el mapa conceptual del ENV según el nuevo enfoque propuesto en Ampliar la mirada. Confirma, por tanto, lo que habíamos propuesto antes: que en el ENV de este enfoque están presentes todas las necesidades humanas, el ser humano completo, pero visto sólo desde la perspectiva económica. Al discutir qué necesidades habrían de ser incluidas en el cuadro, la decisión fue la de incorporar aquellas necesidades del esquema

de Maslow sobre las cuales parece posible postular un consenso. Al hacerlo así partimos del ser humano completo $y$, por tanto, de todas sus necesidades (salvo las estéticas, sobre las cuales no hay consenso). Nos situamos así en el EFH. Nos mantuvimos en este eje en la columna 2, puesto que la identificación de satisfactores es una tarea común a múltiples perspectivas. Fue al añadir la columna 3 y ninguna otra más, cuando de manera implícita hicimos el recorte y nos situamos en la perspectiva económica (recortando las demás) y, por tanto, nos situamos en el ENV.

De aquí se desprende claramente la conclusión de que el contenido del eje de nivel de vida al que por esta vía llegamos es esencialmente distinto al que habríamos construido si lo hubiésemos abordado directamente: hubiésemos implícitamente recortado necesidades y satisfactores y hubiésemos llegado a una visión similar al del enfoque convencional de las necesidades de la EPP. Si esta conclusión fuese correcta, y mi opinión es que sí lo es, habría mostrado que el camino que consiste en abordar el problema de la pobreza directamente en el eje del nivel de vida - sin pasar por el del florecimiento humano, único eje conceptual en el que es dable identificar todas las necesidades (y capacidades) humanas-, camino adoptado por casi todos los estudiosos de la pobreza y que se traduce en un universo recortado de necesidades (y, por tanto, de satisfactores y recursos, como hemos visto), es incorrecto porque supone una visión reduccionista.

Esta conclusión, esta tesis crítica, se convierte en un arma fundamental de la crítica no sólo de los enfoques convencionales de la pobreza, sino también del enfoque de Sen sobre las capabilities-functionings, lo que en efecto ocurrió en la investigación emprendida en Ampliar la mirada.

Tanto el enfoque convencional de necesidades de la pobreza como el de búsquedas fallidas de un nuevo enfoque (éste una vez deconstruido), que se pueden expresar como "sólo 'necesidades' materiales que se satisfacen únicamente con objetos, para lo que se requieren solamente recursos económicos monetizables o, peor aún, sólo ingresos corrientes", conlleva a una concepción parcial incluso de las llamadas necesidades materiales e ignora las inmateriales, es claramente un enfoque "mecanicista", en el cual los seres humanos son vistos como robots 
o como ganado (estabulado). Salvo el caso de alguien que realice todas sus comidas en restaurantes o comedores institucionales, caso muy raro sobre todo en el tercer mundo, alimentarse supone no sólo objetos no duraderos (alimentos) sino las actividades de cocinar y asociadas (abastecimiento y limpieza) y los objetos duraderos implicados (estufa, sartenes, mesa, sillas, platos y cubiertos, por ejemplo) y otros no duraderos (gas, detergentes, por ejemplo). Las actividades y los objetos enumerados distintos a los alimentos son ignorados en este grupo de la EPP. El enfoque economicista dominante, que rechaza el concepto de necesidades, se sitúa en un vacío conceptual que no puede llenar el concepto vacío que es la utilidad. Una síntesis de la crítica de Sen y Rawls a este concepto se presentó en la sección 3 supra.

La medición de la pobreza toma a veces la forma (indirecta) de medición de los recursos del hogar y otras la de observación directa de la (in)satisfacción de necesidades. En ambos casos se puede establecer el vínculo explícito con las necesidades humanas. En el segundo es inevitable hacerlo: hay un momento en el procedimiento en el cual, inevitablemente, se definen las necesidades humanas que se abordarían. En el primero se puede establecer cuando se aborda la definición de la línea (o umbral) de pobreza. Si esta definición se aborda a través de la identificación de canastas normativas completas, como en el método de presupuestos familiares, la vinculación es también inevitable: es necesario definir explícitamente cuáles necesidades se tomarán en cuenta antes de proceder al cálculo de requerimientos de satisfactores. En ambos casos al evaluar la lista de necesidades usada por algún autor como parte de su ejercicio de medición de la pobreza, utilizando como marco de referencia cualquier teoría de las necesidades humanas, será posible apreciar si ha habido o no recorte de necesidades. Por ejemplo, si partiendo del esquema de necesidades de Max Neef identificamos que la lista en cuestión corresponde con las necesidades de subsistencia, protección y entendimiento de Max Neef et al. concluiremos que se han recortado las otras seis necesidades identificadas por ellos (afecto, participación, ocio, creación, identidad y libertad).

Sin embargo, cuando se define la línea de la pobreza de manera arbitraria, como lo hace el Banco Mundial, no se establece tal vínculo. Cuando se parte de una única necesidad, la alimentaria, para establecer una canasta normativa alimentaria y luego obtener la línea o umbral de pobreza multiplicando su costo por un factor, como ocurre en el método que he llamado de la canasta normativa alimentaria (CNA) que utilizan la Comisión Económica para América Latina y el Caribe (CEPAL), el gobierno de Estados Unidos y que utilizó el Comité Técnico para la Medición de la Pobreza de la Secretaría de Desarrollo Social del gobierno federal de México, el vínculo queda truncado ya que se establece con una única necesidad. Como este camino de medición indirecta de la pobreza sin definir canastas normativas completas ha predominado prácticamente en todo el mundo, el recorte no se ha convertido en un tema de discusión, ya que casi todos los que miden la pobreza abordan directamente el eje de nivel de vida, sin pasar por el florecimiento humano.

El círculo argumental se ha completado. La crítica de los enfoques convencionales de la pobreza, la EPP, nos ha llevado a concluir que los enfoques convencionales conllevan un enfoque distorsionado, parcial, del ser humano. Al adoptar el enfoque aquí planteado superamos esta visión distorsionada y parcial y nos acercamos al ser humano completo, con todas sus necesidades.

\section{Bibliografía}

Abel Smith, B. y Peter Townsend, 1965, The Poor and the Poorest, Bell, Londres.

Alkire, Sabina, 2002, Valuing Freedoms. Sen's Capability Approach and Poverty Reduction, Oxford University Press, Oxford.

Altimir, Óscar, 1979, La dimensión de la pobreza en América Latina, CEPAL, Santiago de Chile (Cuadernos de la CEPAL, 27).

Boltvinik, Julio, 1990, Pobreza y necesidades básicas. Conceptos y métodos de medición, Proyecto Regional para la Superación de la Pobreza, PNUD (RLA/86/004), Caracas.

__ 1992, "El método de medición integrada de la pobreza. Una propuesta para su desarrollo", Comercio Exterior, vol. 42, núm. 4, abril, pp. 354-365.

— 2003, "Welfare, Inequality, and Poverty in Mexico, 1970-2000", en Kevin J. Middlebrook y Eduardo Zepeda, Confronting Development. Assessing Mexico's Economic and Social Policy Challenges, Stanford University Press, pp. 385-446. 
_- 2006, Ampliar la mirada. Un nuevo enfoque de la pobreza y el florecimiento humano, libro en preparación basado en la tesis de doctorado, del mismo título, presentada en CIESAS-Occidente, Guadalajara, abril de 2005.

— y Enrique Hernández Laos, 1999, Pobreza y distribución del ingreso en México, Siglo XXI, México.

Bryant, Keith W., 1990, The Economic Organization of the Household, Cambridge University Press, Cambridge, Reino Unido.

Citro, Constance F. y Robert T. Michael (eds.), 1995, Measuring Poverty. A New Approach, National Research Council, National Academy Press, Washington.

Cohen, Gerald A., 1993, "Equality of What? On Welfare, Goods and Capabilities", en M. Nussbaum y A. Sen, The Quality of Life, Clarendon Press, Oxford, pp. 9-29. (En español: Calidad de vida, Fondo de Cultura Económica, México, 1998. Una traducción independiente de extractos del capítulo de Cohen fue publicada en Comercio Exterior, vol. 53, núm. 5, mayo de 2003, pp. 427-433.)

Crocker, David, 1995, "Functioning and Capability: The Foundations of Sen's and Nussbaum's Development Ethic. Part 2", en M. Nussbaum y J. Glover (eds.), Women, Culture and Development. A Study of Human Capabilities, Clarendon Press, Oxford.

Deaton, Angus y John Muellbauer, 1991 [1980], Economics and Consumer Behavior, Cambridge University, Cambridge, Massachusetts.

Desai, Meghnad, 1994, "Poverty and Capabilities: Toward an Empirically Implementable Measure", Frontera Norte, vol. 6, núm. especial "La pobreza”, El Colegio de la Frontera Norte, Tijuana, pp. 11-30.

Doyal, Len e Ian Gough, 1991, A Theory of Human Need, Macmillan, Londres.

Gasper, Des, 2004, The Ethics of Development, Edinburgh University Press, Edimburgo.

Hagenaars, Aldi M., 1986, The Perception of Poverty, NorthHolland, Amsterdam.

Márkus, György, 1985, Marxismo y 'antropología', Grijalbo, México. (Edición previa en Grijalbo, Barcelona, 1973.)

- 1986, Language and Production. A Critique of the Paradigms, D. Reidel Publishing Company, Dordrecht, Países Bajos.

Maslow, Abraham, 1943, "A Theory of Human Motivation”, Psychological Review, vol. 50, pp. 370-396.

— 1978 [1954], Motivation and Personality, 3a ed., Addison-Wesley Longman, Nueva York.

Max Neef, Manfred et al., 1986, Desarrollo a escala humana. Una opción para el futuro, núm. especial de Development Dialogue, Uppsala, Suecia, y Santiago de Chile.

Nussbaum, Martha, 2000, Women and Human Development. The Capabilities Approach, Cambridge University Press, Cambridge, Reino Unido, pp. 11-14.
, 2006, Frontiers of Justice. Disability, Nationality, Species Membership, Harvard University Press, Cambridge, Massachussets.

Penz, G. Peter, 1986, Consumer Sovereignity and Human Interests, Cambridge University Press, Cambridge.

Ravaillon, Martin, 1998, "Poverty Lines in Theory and Practice”, Living Standards Measurement Study, working paper núm. 133, Banco Mundial, Washington.

Pogge, Thomas, 2002, World Poverty and Human Rights, Polity Press, Cambridge, Reino Unido.

Ravallion, Martin, 1998, "Poverty Lines in Theory and Practice”, Living Standards Measurements Study, Banco Mundial, Washington (Working Paper, 133).

Sen, Amartya K., 1980, “Equality of What?”, en McMurrin (ed.), The Tanner Lectures on Human Values, Cambridge University Press, Cambridge. (Reproducido en Amartya Sen, Choice, Welfare and Measurement, 1997, pp. 353369.)

— 1985, Commodities and Capabilities, North-Holland, Amsterdam.

, 1987, The Standard of Living, Cambridge University Press, Cambridge, Reino Unido.

__, 1992, Inequality Reexamined, Harvard University Press, Cambridge, Massachussets.

, 1993, “Capability and Well Being”, en M. Nussbaum y A. Sen, Quality of Life, Clarendon Press, Oxford, pp. 3153. (En español: Calidad de vida, Fondo de Cultura Económica, México, 1998.)

_, 2003 , "Pobre, en términos relativos", Comercio Exterior, vol. 53, núm. 5, mayo.

- y James Foster, 1997, On Economic Inequality, Oxford University Press, Oxford.

Stewart, Frances, 1996, "Basic Needs, Capabilities, and Human Development", en Avner Offer, In Pursuit of the Quality of Life, Clarendon Press, Oxford.

Townsend, Peter, 1979a, Poverty in the United Kingdom, Penguin, Harmondsworth, Reino Unido.

__ 1979b, "The Development of Research on Poverty", Social Security Research: The Definition and Measurement of Poverty, HMSO, Londres.

Warr, P., 1987, Work, Unemployment and Mental Health, Clarendon Press, Oxford.

Wiggins, David, 2002 [1987], Needs, Values, Truth. Essays in the Philosophy of Value, Clarendon Press, Oxford.

Williams, Bernard, 1987, "Professor Sen on the Capability Approach", en Sen, The Standard of Living, Cambridge University Press, Cambridge, Reino Unido. (Una traducción de extractos del texto de Williams fue publicada en Comercio Exterior, vol. 53, núm. 5, mayo de 2003.) 